Andrews University

Digital Commons @ Andrews University

Faculty Publications

$5-11-2020$

\title{
Kinetic insights into the lignocellulosic biomass-based levulinic acid production by a mechanistic model
}

\author{
Emília Savioli Lopes \\ Universidade Estadual de Campinas \\ Elmer Ccopa Rivera \\ Andrews University, ccoparivera@andrews.edu \\ Julio César de Jesus Gariboti \\ Universidade Federal de Sao Paulo \\ Luis Henrique Zimmermann Feistel \\ Universidade Federal de Santa Maria \\ João Vitor Dutra \\ Universidade Federal de Santa Maria
}

See next page for additional authors

Follow this and additional works at: https://digitalcommons.andrews.edu/pubs

Part of the Biochemical and Biomolecular Engineering Commons

\section{Recommended Citation}

Lopes, Emília Savioli; Ccopa Rivera, Elmer; de Jesus Gariboti, Julio César; Feistel, Luis Henrique Zimmermann; Dutra, João Vitor; Maciel Filho, Rubens; and Tovar, Laura Plazas, "Kinetic insights into the lignocellulosic biomass-based levulinic acid production by a mechanistic model" (2020). Faculty Publications. 1571.

https://digitalcommons.andrews.edu/pubs/1571

This Article is brought to you for free and open access by Digital Commons @ Andrews University. It has been accepted for inclusion in Faculty Publications by an authorized administrator of Digital Commons @ Andrews University. For more information, please contact repository@andrews.edu. 


\section{Authors}

Emília Savioli Lopes, Elmer Ccopa Rivera, Julio César de Jesus Gariboti, Luis Henrique Zimmermann Feistel, João Vitor Dutra, Rubens Maciel Filho, and Laura Plazas Tovar 


\title{
Kinetic insights into the lignocellulosic biomass-based levulinic acid production by a mechanistic model
}

\author{
Emília Savioli Lopes (10 - Elmer Ccopa Rivera • Julio César de Jesus Gariboti • \\ Luis Henrique Zimmermann Feistel · João Vitor Dutra · Rubens Maciel Filho (D) \\ Laura Plazas Tovar (i)
}

Received: 23 December 2019/Accepted: 20 April 2020/Published online: 11 May 2020

(C) Springer Nature B.V. 2020

\begin{abstract}
In this work, a mechanistic model was developed to simulate the kinetics of the production of levulinic acid (LA) from sugarcane bagasse (SCB), rice husk $(\mathrm{RH})$ and soybean straw (SS). The production of LA from those agro-industrial wastes followed the methodology of biorefining in three stages. Experimental data from the third stage (catalytic depolymerization of cellulose) obtained under a wide range of operating conditions were used to estimate the parameters of the model. An optimization procedure based on a genetic algorithm was used to determine the optimal parameter values. The prediction of the concentrations of glucose, 5-HMF and LA using the mechanistic model was particularly accurate, as demonstrated by $\mathrm{R}^{2}$ and RMSE. Thereby, a satisfactory concordance was reached between the
\end{abstract}

E. S. Lopes - E. C. Rivera - R. Maciel Filho

School of Chemical Engineering, University of Campinas, Campinas, SP 13083-852, Brazil

E. C. Rivera

Department of Engineering, Andrews University,

Berrien Springs, MI 49104, USA

J. C. de Jesus Gariboti · L. P. Tovar $(\bowtie)$

Department of Chemical Engineering, Federal University

of São Paulo, Diadema, SP 09913-030, Brazil

e-mail: laura.tovar@unifesp.br

L. H. Z. Feistel · J. V. Dutra

Department of Chemical Engineering, Federal University

of Santa Maria, Santa Maria, RS 97105-900, Brazil high yields of LA of $61.1 \mathrm{~mol} \%, 67.7 \mathrm{~mol} \%$ and $61.4 \mathrm{~mol} \%$ calculated by the model, and the experimental yields of $60.5 \pm 2.1 \mathrm{~mol} \%, 65.2 \pm 2.9 \mathrm{~mol} \%$ and $61.5 \pm 4.0 \mathrm{~mol} \%$ (under optimum conditions of $190{ }^{\circ} \mathrm{C}, 7.0 \% \mathrm{w} / \mathrm{v}$ of $\mathrm{H}_{2} \mathrm{SO}_{4}, 75 \mathrm{~min}$ ) for SCB, $\mathrm{RH}$ and $\mathrm{SS}$, respectively. The biorefining of the agro-industrial wastes under optimum operating conditions allowed a satisfactory catalytic depolymerization of cellulose, regardless of the degree of crystallinity. The estimation of yields led to suggesting a strategy from the point of view of process synthesis and design, integrating SCB, RH and SS to supply their off-season and, thus, to ensure the supply of raw materials in the production of LA. 


\section{Graphic abstract}

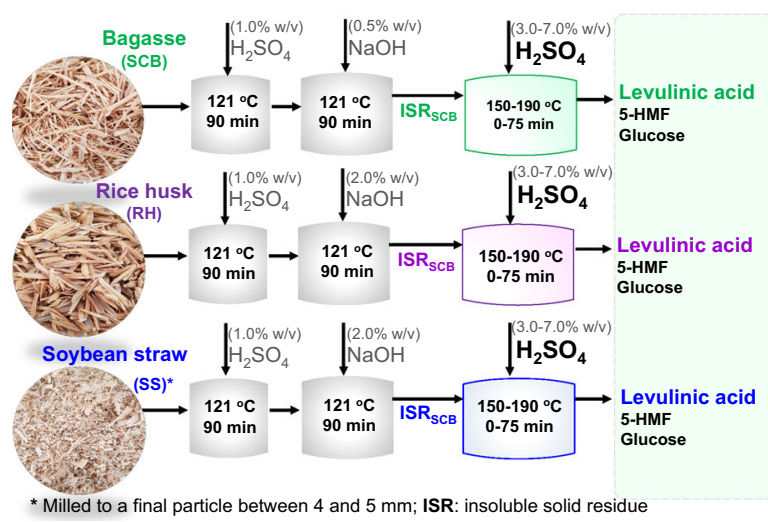

Keywords Agro-industrial waste - Estimation of kinetic parameters · Genetic algorithm · Levulinic acid - Mathematical modeling - Process synthesis and design

\section{Introduction}

Harnessing crop residues for food or biofuels, here called agro-industrial waste, can add value to a particular agricultural operation. In terms of economic valorization, the biorefining of agro-industrial waste for producing levulinic acid aims at its strategic participation in the chemical industry as an input (for instance, as a precursor to monomers as levulinic acid esters) (Rivas et al. 2019), as a primary product in sectors such as fine chemistry (Lappalainen and Dong 2019) and as precursor to hydrocarbon fuel in the industry of biofuels (Mukherjee et al. 2015). Levulinic acid has a significant potential to generate additional revenues, representing an opportunity for agribusiness in the industries of sugarcane, rice and soybeans. Brazil is currently the world's largest sugarcane producer, with a forecast of producing about 602 million tons of sugarcane in the 2019-2020 harvest (from April to November) (Udop 2019). It corresponds to a production of nearly 182 million tons of sugarcane bagasse. In addition, Brazil, as the main producer of rice within the Southern Common Market (Mercosur-South American trade bloc) (USDA 2019), is expected to produce around 11.6 million tons of rice in the 2019-2020 crop (January to June). About 20-25\% of the grain weight corresponds to husk, resulting in an

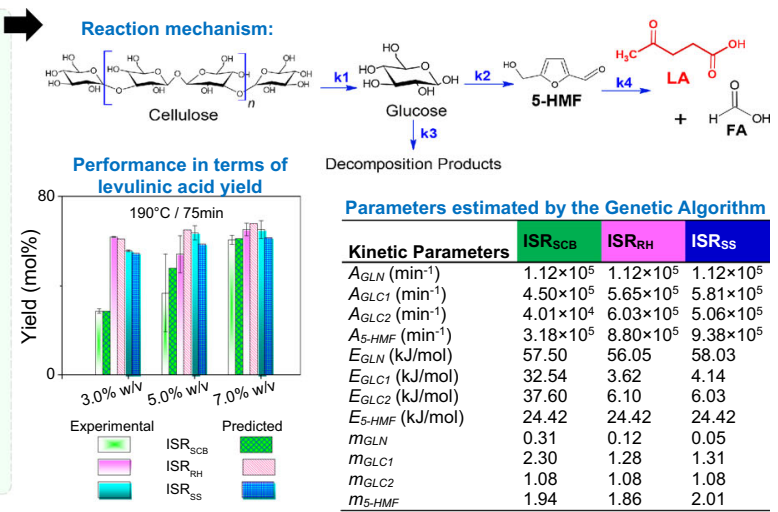

estimated production of 2.5 million tons. Brazil is also the second largest producer of soybeans, which is considered one of the main agricultural commodities traded in international markets. A production of 125 million tons of soybeans is expected during the 2019-2020 crop (January to May), which is equivalent to about $30 \%$ of the total produced in the world (MAPA 2019). Soybean straw has a ratio of 1:1.2-1:1.5 with soybean harvested, giving this waste an expressive economic potential. In this context, Brazil's favorable position in the global agribusiness scenario stands out, where sugarcane, rice and soybeans are the main agricultural crops (Islam et al. 2018). In the same scenario, the most explored lignocellulosic biomasses are rice straw and husk, wheat straw, sugarcane bagasse, corn husk and sorghum bagasse (Haldar and Purkait 2020). The increased production of biofuels and chemical products based on the above-mentioned food crops and their effect on land use has given rise to the discussion about food and biofuels/chemical products. This discussion is mainly based on the premise that the increase of land for producing biofuels/chemical products would affect the prices and the availability of food. In this sense, the production of levulinic acid from agro-industrial waste, which cannot be used as food, can contribute to the reconciliation of the production of large amounts of food and biofuels/chemical products.

Previous works have suggested three routes for producing levulinic acid. The first one involves the petrochemical conversion of maleic anhydride (Rackemann and Doherty 2011). The second route involves a series of acid catalyzed reactions from 
hemicelluloses (Wang et al. 2018). In those reactions, the high reactivity of the catalytic depolymerization of furfuryl alcohol cellulose results in a relatively low selectivity of levulinic acid, due to undesirable byproducts (Fleig et al. 2018). The third way, addressing several reaction mechanisms (Table 1; Fig. 1), includes the triple dehydration of hexoses. Typically, this route leads to an increase in the yield of levulinic acid. The synthesis of levulinic acid occurs by means of serial acid hydrolysis reactions, including the dehydration of hexoses formed during the decomposition of cellulose until 5-HMF, followed by a reaction of rehydration for the production of levulinic acid and formic acid (FA) (Weingarten et al. 2012).

One of the main challenges of producing levulinic acid is determining the effect of its operating conditions on kinetic behavior, which clearly affects both process and performance. Although different empirical studies have been developed to improve the production process, they do not have a systematic model-based approach. A realistic kinetic model for the accurate and efficient estimation of kinetic parameters is required to perform process control and optimization.

Table 1 shows the estimated kinetic parameters of levulinic acid production using various substrates and acid catalysts under different operating conditions. In most of the cases cited in this table, the kinetics of each reaction was described by two coefficients: the preexponential factor $\left(A_{i}\right)$ and activation energy $\left(E_{A i}\right)$, assuming a first order reaction (Shen and Wyman 2012; Weingarten et al. 2012; Rivas et al. 2014; Fachri et al. 2015; Ren et al. 2015; Mukherjee and Dumont 2016; Tan-Soetedjo et al. 2017). In addition, some studies (Chang et al. 2006; Lenihan et al. 2011), despite having established that the order of reaction $\left(m_{i}\right)$ differs from 1, do not describe the kinetics of levulinic acid production under this consideration. The accurate estimation of kinetic parameters is an important issue in the development of mechanistic models. Kinetic parameters estimated from a wide range of operating conditions would allow to reduce the uncertainty of the models under operating conditions not yet established (Sikalo et al. 2015). The work of Girisuta et al. (2013) addressed the gaps of models previously reported in literature. However, this model limits its application to the conditions in the range studied and to the substrate evaluated by the authors (sugarcane bagasse). Since the problem of estimating the kinetic parameters of the model is complex, an optimization procedure based on a genetic algorithm can be used to determine the optimal parameter values.

The use of meta-heuristic algorithms such as the genetic algorithm (GA) for estimating a significant number of kinetic parameters has been attracting a particular interest in recent years. Das et al. (2014) used GAs to gain a better mechanistic understanding of the catalytic reaction involved in dilute sulfuric acid pre-treatment of water hyacinth biomass. GA was also used by Sikalo et al. (2015) for optimizing the reaction mechanisms of hydrogen, methane and tert-butanol. Punnathanam et al. (2016) applied GA in the integration of a biorefinery consuming the effluent Black Liquor from a plant of paper and cellulose for producing electricity and steam. Later, Darkwah et al. (2018) applied GA as a process engineering tool in the design and optimization of fermentation-based biorefineries. Ding et al. (2019) used GA for estimating the kinetic reaction parameters of beech wood pyrolysis. Curiously, despite the several applications of GA in the study of high complexity reaction systems, its use in the context of producing levulinic acid has not yet been explored.

This study investigates a wide range of operating conditions in the production kinetics of levulinic acid, from agro-industrial waste (AIW), such as sugarcane bagasse, rice husk and soybean straw. For this, a mechanistic model was developed, with kinetic parameters determined by an optimizing procedure based on a genetic algorithm. The model was validated by means of experiments performed by the threestages biorefining process, which are the acid pretreatment, the alkaline pre-treatment and the catalytic depolymerization of cellulose (Fleig et al. 2018). The proposed methodology aims to promote the efficient conversion of biomass into bio-based resources through the development of a reliable mechanistic model for the levulinic acid production process from agro-industrial waste.

\section{Materials and methods}

Agro-industrial waste

Sugarcane bagasse (SCB) was provided by a sugarenergy group from Araras, state of São Paulo, Brazil $\left(22^{\circ} 25^{\prime} 35.2^{\prime \prime} \mathrm{S} 47^{\circ} 21^{\prime} 32.9^{\prime \prime} \mathrm{W}\right)$. Rice husk (RH) was 


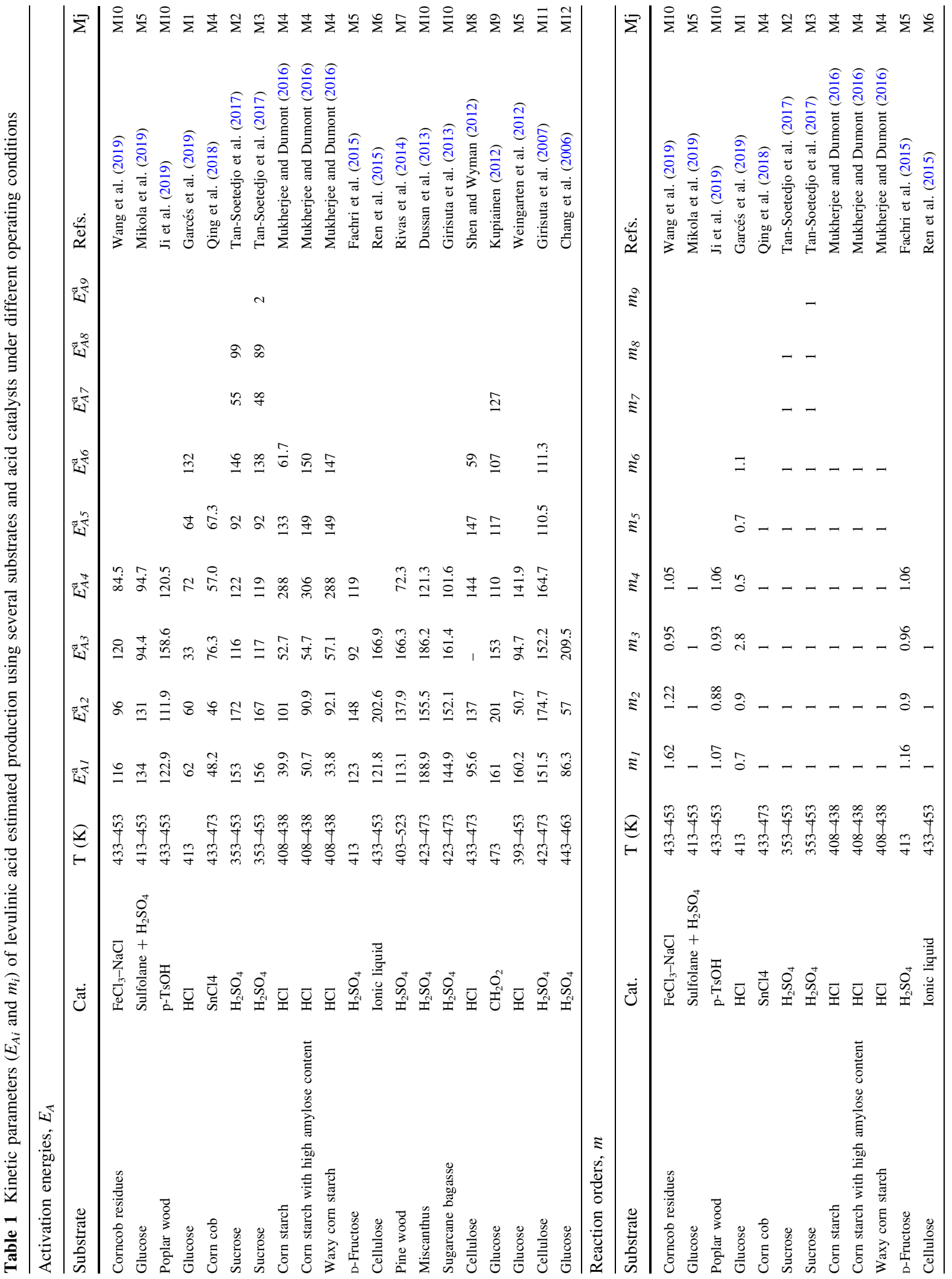




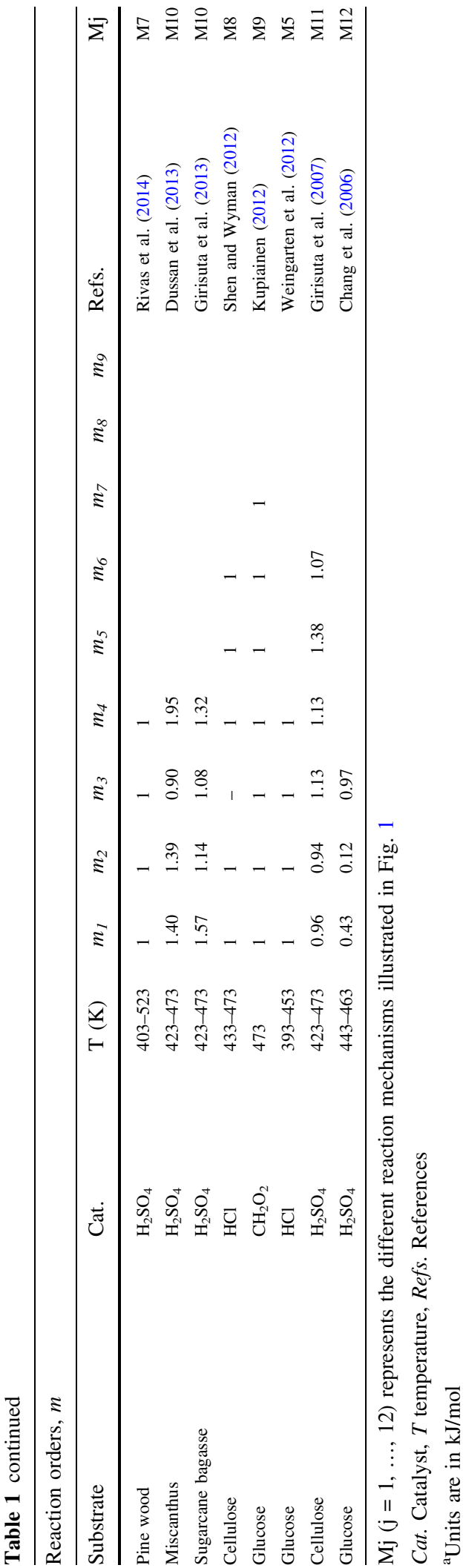

collected from an agricultural field near Santa Maria, state of Rio Grande do Sul, Brazil $\left(29^{\circ} 42^{\prime} 09.5^{\prime \prime}\right.$ S $53^{\circ} 41^{\prime} 58.2^{\prime \prime} \mathrm{W}$ ). Soybean straw (SS) was supplied by Seeds Research Center of Júlio de Castilhos, state of Rio Grande do Sul, Brazil (rural zone $29^{\circ} 13^{\prime} 36.0^{\prime \prime} \mathrm{S}$ $\left.53^{\circ} 40^{\prime} 54.0^{\prime \prime} \mathrm{W}\right)$. All AIWs were air dried under sunlight until a final moisture content of $<11 \%$ in weight. Only SS was milled until a final particle between 4 and $5 \mathrm{~mm}$. The composition of SCB, RH and SS was determined using the National Renewable Energy Laboratory (NREL) protocols (Sluiter et al. 2008a, b, 2012), and the SCB lignin analysis followed the methodology proposed by Gouveia et al. (2009). All chemical agents used in this study were of analytic grade and used without purification.

\section{Levulinic acid production}

The production of levulinic acid from the lignocellulosic material of agro-industrial waste followed the three-stages biorefining methodology (acid pre-treatment, alkaline pre-treatment and catalytic depolymerization of cellulose), which is consistent with the concept of biorefinery (Fleig et al. 2018). The first stage consists in the pre-hydrolysis of the lignocellulosic material, in a solution of $\mathrm{H}_{2} \mathrm{SO}_{4}(1.0 \% \mathrm{w} / \mathrm{v})$ and temperature of $121{ }^{\circ} \mathrm{C}$ (in autoclave) during $90 \mathrm{~min}$. A ratio liquid:solid of 6.7 (with $15 \mathrm{~g}$ of dry basis lignocellulosic material) was used. The suspension was then filtered and separated into a liquid fraction [acid hydrolyzate (AH-I)] and in a fraction of water insoluble solids (WIS). The hydrolyzed solid fraction was executed at the second stage of the process. In this stage, the solids were treated with $\mathrm{NaOH}(0.5 \%$ w/v for SCB and $2.0 \% \mathrm{w} / \mathrm{v}$ for $\mathrm{RH}$ and $\mathrm{SS}$ ), and temperature of $121{ }^{\circ} \mathrm{C}$ (in autoclave) during $90 \mathrm{~min}$. A liquid:solid ratio of 6.7 (with $15 \mathrm{~g}$ of WIS in dry basis) was used. This stage allowed to solubilize most of the lignin (in greater quantity in SCB) and the ashes (in greater quantity of $\mathrm{RH}$ and SS), generating a black liquor (BL) and insoluble solid residues (ISR). These residues are identified as $\mathrm{ISR}_{\mathrm{SCB}}, \mathrm{ISR}_{\mathrm{RH}}$ and $\mathrm{ISR}_{\mathrm{SS}}$, for sugarcane bagasse, rice husk and soyabean straw, respectively. The composition in dry basis of WIS and ISRs was determined using NREL protocols (Sluiter et al. 2008a, 2012) and the SCB lignin analysis followed the protocol proposed by Gouveia et al. (2009). A portion of the ISR was finally pulverized (particles $<0.149 \mathrm{~mm}$ ). The ISR crystallinity index 

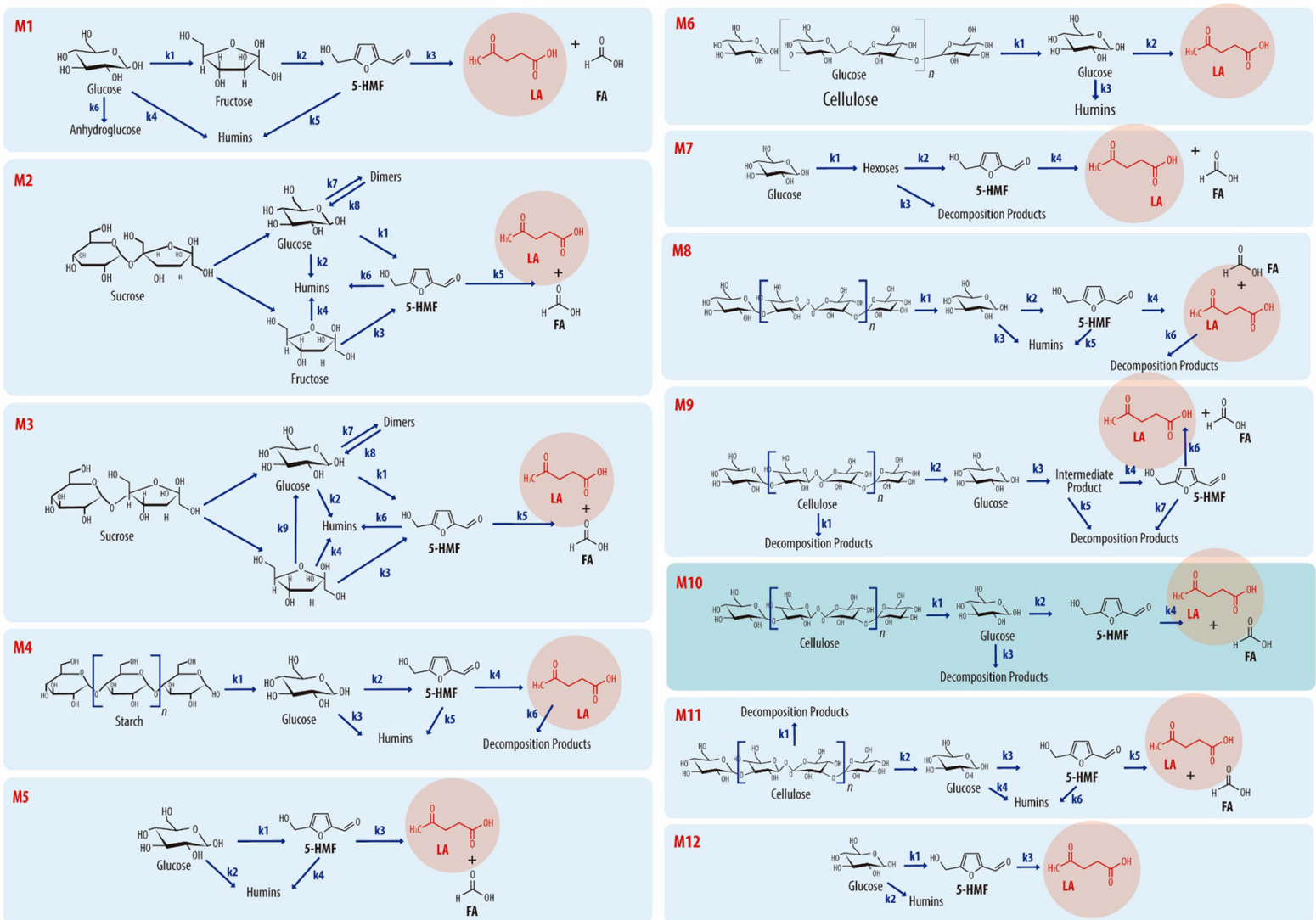

M12

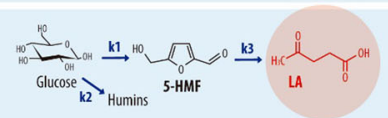

Fig. 1 Schematic representation of the reaction mechanisms describing the production of levulinic acid from different substrates. Intermediate and side reactions as well as reacion rate constants $k_{i}$ are also detailed

reference values were determined by XRD. The diffractograms were recorded using an X-ray diffractometer with cooper $\mathrm{K} \alpha$ radiation, $30 \mathrm{kV}$ voltage $20 \mathrm{~mA}$ current. All tests were performed at a rate of $1 \%$ min over a scan interval $(2 \theta)$ between $5^{\circ}$ and $50^{\circ}$. The relative crystallinity index $(\mathrm{CrI})$ was calculated using the Segal et al. method's (Segal et al. 1959).

Insoluble solid residues (ISRs) were directed to the third stage of the proposed biorefining, which consists in the catalytic depolymerization of cellulose using $\mathrm{H}_{2} \mathrm{SO}_{4}$ under different concentrations. Initially, a $5 \mathrm{~g}$ sample of ISR (in dry basis) was disposed in a Teflon beaker for hydrothermal cells. Subsequently, a specified volume of an aqueous $\mathrm{H}_{2} \mathrm{SO}_{4}$ solution (concentrations of $3.0 \% \mathrm{w} / \mathrm{v}, 5.0 \% \mathrm{w} / \mathrm{v}$ and $7.0 \% \mathrm{w} / \mathrm{v}$ ) was added to obtain a liquid:solid ratio of 10 . The Teflon beaker, with the suspension, was then transferred to a $316 \mathrm{~L}$ stainless steel reactor. Finally, the reactor was sealed and then placed in an oil bath until the desired temperature was reached $\left(150{ }^{\circ} \mathrm{C}, \quad 170{ }^{\circ} \mathrm{C}\right.$ and $\left.190{ }^{\circ} \mathrm{C}\right)$.

Under these conditions, the experiments of the third stage of biorefining were performed at different time intervals $(0,15,30,45$ and $75 \mathrm{~min})$. Samples collected from the acid hydrolysis (AH-II) containing levulinic acid for each experiment performed were filtered through membranes $(0.22 \mu \mathrm{m}$ PVDF). The ones filtered were transferred to clean flask and kept in the freezer for further chromatographic analysis.

Analytical methods

All measurements of sugar concentrations (glucose, cellobiose, xylose and arabinose), organic acids (acetic, formic and levulinic) and furans (5-HMF and furfural) were carried out by high performance liquid chromatography (HPLC). The method and the equipment are described in Fleig et al. (2018). 


\section{Mathematical modeling and parameter estimation}

The mechanistic model describing the kinetics of levulinic acid production was developed with experimental data from the third stage of the proposed process of biorefining. This stage consists in the catalytic depolymerization of cellulose for producing levulinic acid from insoluble solids residues (ISR).

Kinetics and theoretical aspects of the synthesis of levulinic acid

The need for elevated temperatures and acid catalysis is due to the crystalline structure, as well as to intramolecular and intermolecular hydrogen bonds of the cellulose present in ISR. The most accepted mechanism for catalytic cellulose depolymerization is the M10 reaction mechanism (Van de Vyver et al. 2011) shown in Fig. 1. This mechanism works by protonation of glycosidic oxygen to break the $\beta$-1,4-glycosidic bond water-soluble oligomers and then to glucose. The synthesis of levulinic acid occurs by means of serial acid hydrolysis reactions, including the dehydration of hexoses formed during the decomposition of cellulose to 5-HMF, followed by a rehydration reaction for the production of levulinic acid and formic acid (Van de Vyver et al. 2011). The kinetic model adopted in this study (Girisuta et al. 2013), was developed based on the M10 reaction mechanism.

The main premises of the mechanistic model describing the kinetics of the production of levulinic acid are as follows:

- Constant volume batch reactor.

- Catalytic depolymerization of cellulose from insoluble solid residues (ISR) as a function of temperature, reaction time and concentration of acid solution.

- Irreversible homogeneous reaction.

- Effects of different ISR particles sizes were neglected.

- Temperature and concentration of acid solution are uniform in the reactor.

The mechanistic model describes the substrate concentration kinetics (glucan/cellulose)-GLN (g/ L), glucose-GLC (g/L), 5-hydroxymethylfurfural5-HMF $(\mathrm{g} / \mathrm{L})$, levulinic acid-LA $(\mathrm{g} / \mathrm{L})$ and huminsHUs $(\mathrm{g} / \mathrm{L})$, in terms of five ordinary differential equations, Eqs. (1)-(5) (Girisuta et al. 2013).

$$
\frac{d[G L N]}{d t}=-k_{G L N}[G L N]
$$

$\frac{d[G L C]}{d t}=k_{G L N}[G L N]-\left(k_{G L C 1}+k_{G L C 2}\right)[G L C]$

$\frac{d[5-H M F]}{d t}=k_{G L C 2}[G L C]-k_{5-H M F}[L A]$

$\frac{d[L A]}{d t}=k_{5-H M F}[5-H M F]$

$\frac{d[H U s]}{d t}=k_{G L C 2}[G L C]$

where $k_{G L N}$ is the constant of the reaction rate of the conversion of glucan (GLN) into glucose (GLC) $\left(\mathrm{min}^{-1}\right), k_{G L C l}$ is the constant of the reaction rate of the conversion of glucose (GLC) into 5-HMF $\left(\mathrm{min}^{-1}\right.$ ), $k_{G L C 2}$ is the constant of the reaction rate of the conversion of glucose (GLC) into decomposition products (HUs) $\left(\mathrm{min}^{-1}\right), k_{5-H M F}$ is the constant of the reaction rate of the conversion of 5-hydroxymethylfurfural (5-HMF) into levulinic acid (LA) $\left(\min ^{-1}\right)$, and $t$ is the reaction time (min).

Reaction rate constants can be expressed by means of a modified Arrhenius equation (Eq. 6), which combines the effects of temperature and concentration of $\mathrm{H}_{2} \mathrm{SO}_{4}$ :

$k_{i}=A_{i} \exp \left(\frac{-E_{A_{i}}}{R T}\right)(\text { acid })^{m_{i}}$

where $A_{i}\left(\mathrm{~min}^{-1}\right)$ is the frequency factor, $E_{A i}$ is the activation energy $(\mathrm{kJ} / \mathrm{mol}), m_{i}$ is the reaction order of reaction of the hydronium ion concentration, $T$ is the temperature (K), acid is the concentration of $\mathrm{H}_{2} \mathrm{SO}_{4}$ (weight per volume fraction) and $R$ is the ideal gas constant.

Parameter estimation method using the genetic algorithm

The parameter estimation method comprises, first, a sensitivity analysis of the kinetic model adopted in this study (Eqs. 1-5). The sensitivity analysis aims to determine a subset of kinetic parameters of the model with the greatest effect on responses, concentration of GLC, 5-HMF and LA. The technique used was a one-at-a-time sensitivity analysis where each kinetic parameter varies independently while the other 
parameters remain constant, according to a preestablished simulation scenario. The local effect of a kinetic parameter $P_{j}$ on the response $Y_{i}$, in time $t$ is described by sensitivity factor $J_{i j}$ in Eq. (7). A sensitivity matrix $J$ was then built, where each column described the sensitivity of all responses regarding a reference parameter.

$J_{i j}(t)=\frac{\partial Y_{i}(t)}{\partial P_{j}}$

In this study, each parameter was varied within $\pm 10 \%$ and $\pm 25 \%$ of the nominal values reported in Girisuta et al. (2013). Operating conditions for simulations were: temperature of $150{ }^{\circ} \mathrm{C}$, concentration of $\mathrm{H}_{2} \mathrm{SO}_{4}$ of $5.2 \% \mathrm{w} / \mathrm{v}$ and reaction time of $150 \mathrm{~min}$.

Once the kinetic parameters with the greatest effects on the model responses were determined, the estimation of the optimal values of these parameters was performed using a genetic algorithm (GA) based on the PIKAIA routine (Charbonneau and Knapp 2002). This algorithm solved a problem of non-linear optimization where the objective function defined by Eq. (8) is minimized.

$F O(\theta)=\sum_{i}^{n e p} \sum_{j}^{n s p}\left(\right.$ error $\left.^{2}\right)$

where $\theta$ is the vector containing all parameters, nep is the number of experimental profiles and $n s p$ is the number of experimental sampling points. The error is defined by Eq. (9).

error $=\frac{S_{j, i}^{\text {Predicted }}-S_{j, i}^{\text {Experimental }}}{S_{i}^{\mathrm{Ult}}}$

where $S_{j, i}^{\text {Experimental }}$ is the ith measured concentration, in other words, the measured concentrations of $G L C, 5$ $H M F$ and $L A$ at the time of sampling $j, S_{j, i}^{\text {Predicted }}$ and $S_{j, i}^{\mathrm{Ult}}$ are the concentrations calculated by the kinetic method and the final measured concentration, respectively.

The efficient performance of GA is widely determined by the values of its parameters; therefore, they were defined as follows: The mutation and crossover probabilities were established based on literature values (Charbonneau and Knapp 2002). The definition of the maximum number of generations (GI) or iterations, and the number of individuals in the initial population (IP) was made using a two-level central composite design (CCD). In this design, the influence of GI and IP on the correlation coefficient $\left(\mathrm{R}^{2}\right)$ and on the root-mean-square error (RMSE) was evaluated. $\mathrm{R}^{2}$ and RMSE were used as performance measurements of the kinetic model (Eqs. 1-5) for predicting the experimental data of Girisuta et al. (2013). In CCD the extremes for low and high adjustments for each factor (GI or IP) were established according to the defined intervals ( $59<\mathrm{GI}<341 ; 50<\mathrm{IP}<110$ ).

Once GI and IP are adjusted, the genetic algorithm accelerates the convergence for the calculation of the optimal values of the parameters producing the best adjustment among the concentrations measured of GLC, 5-HMF and LA, and their corresponding concentrations calculated by the kinetic model, minimizing $F O(\theta)$.

The kinetic model coded in FORTRAN (Eqs. 1-5) was integrated using the routine IVPRK (initial value problem, Runge-Kutta method) to obtain the concentration profiles of GLC, 5-HMF and LA. The same routine has already been used in a previous work (Neto et al. 2013). Estimation of kinetic parameters using GA, coupled to the model, was made in a Intel ${ }^{\circledR}$ Core $^{\mathrm{TM}}$ i7-4790 CPU@3.60 GHz.

\section{Results and discussion}

Experimental results of biorefining in three stages

The three-stages biorefining methodology: (1-acid pretreatment, 2-alkaline pretreatment and 3-cellulose catalytic depolymerization) (Fleig et al. 2018) was used for producing levulinic acid (LA) from agroindustrial waste (AIW) such as sugarcane bagasse $(\mathrm{SCB})$, rice rusk $(\mathrm{RH})$ and soybean stray $(\mathrm{SS})$. Table 2 shows the chemical composition (in dry basis) of the integral lignocellulosic material for each AIW, from the fraction of water insoluble solids (WIS) obtained after the first stage, and of insoluble solid residues (ISR) obtained after the second stage. The crystallinity index (CrI) of ISR is also shown in the table. All data represent the average \pm standard deviation of three independent experiments.

In the first stage, the $\mathrm{WIS}_{\mathrm{SCB}}, \mathrm{WIS}_{\mathrm{RH}}$ and $\mathrm{WIS}_{\mathrm{SS}}$ had a recovery of solids of $58.8 \%, 73.8 \%$ and $53.6 \%$, respectively. In this stage happened, mainly, the solubilization of hemicelluloses. The content of hemicelluloses decreased by $76 \%$ in WIS $_{\mathrm{SCB}}$ 


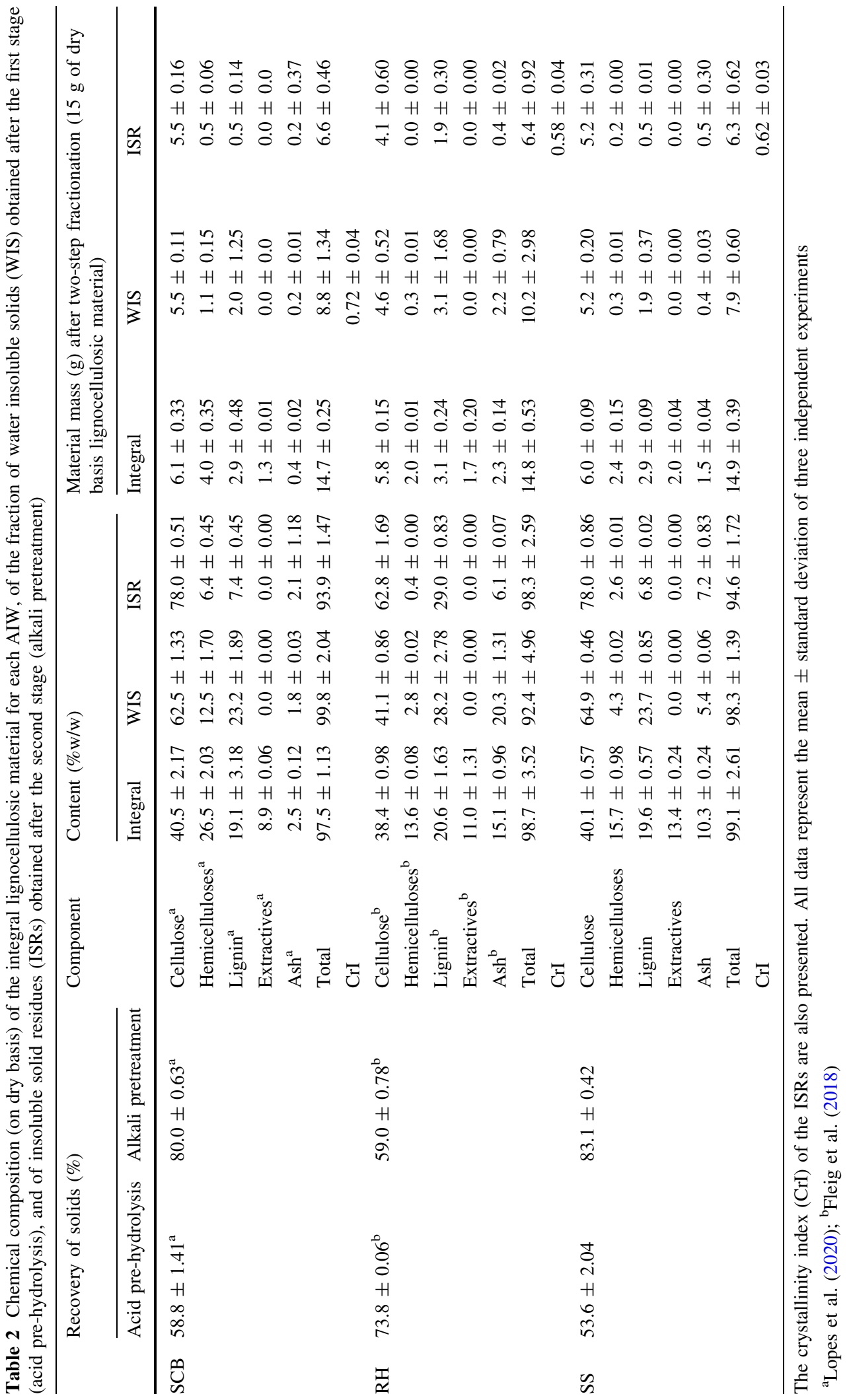


regarding the integral lignocellulosic material of SCB, and by $84.6 \%$ and $85.4 \%$ in $\mathrm{WIS}_{\mathrm{RH}}$ and $\mathrm{WIS}_{\mathrm{SS}}$, respectively, regarding the integral lignocellulosic material of RH and SS. Cellulose and lignin were recovered mainly in solid fractions. The preservation of cellulose in $\mathrm{WIS}_{\mathrm{SCB}}$, WIS $\mathrm{WH}_{\mathrm{RH}}$ and $\mathrm{WIS}_{\mathrm{SS}}$ was of $91 \%, 79 \%$ and $87 \%$, respectively.

On the second stage, the $\mathrm{ISR}_{\mathrm{SCB}}, \mathrm{ISR}_{\mathrm{RH}}$ and ISR $\mathrm{SS}$ (insoluble solids residues of $\mathrm{SCB}, \mathrm{RH}$ and $\mathrm{SS}$, respectively) had a recovery of solids of $80 \%, 59 \%$ and $83.1 \%$, respectively. In this stage, a significant solubilization of lignin occurred. The solubilization of lignin in $\mathrm{ISR}_{\mathrm{SCB}}$, ISR $\mathrm{RH}_{\mathrm{RH}}$ and ISR $\mathrm{SS}$ was of $82 \%, 39 \%$ and $85 \%$, respectively, regarding the integral lignocellulosic materials. The removal of ashes in $\mathrm{ISR}_{\mathrm{SCB}}$, $\mathrm{ISR}_{\mathrm{RH}}$ and $\mathrm{ISR}_{\mathrm{SS}}$ was of $7 \%, 82 \%$ and $42 \%$, respectively. The preservation of cellulose in $\mathrm{ISR}_{\mathrm{SCB}}, \mathrm{ISR}_{\mathrm{RH}}$ and $\mathrm{ISR}_{\mathrm{SS}}$ was of $91 \%, 71 \%$ and $87 \%$, respectively, favoring the production of levulinic acid (LA) from the catalytic depolymerization of cellulose (third stage of biorefining). The study of LA production in stage 3 was addressed in this study using a mechanistic model described in the following sections.

\section{Sensitivity analysis results}

The parameter estimation procedure initially considered evaluating the reliability of the kinetic model adopted in this study (Girisuta et al. 2013). This evaluation included the sensitivity analysis of the model using the technique named one-at-a-time sensitivity analysis. Table 3 shows the calculated sensitivity matrix, where each column described the sensitivity of the LA, GLC and 5-HMF responses to the variation of each kinetic parameter (reference values of the parameters are from Girisuta et al. (2013). The kinetic parameters that generated the most positive or negative values in the sensivity matrix were considered to have the greatest effects on the responses. Sensitivity values were calculated from the increase or decrease of reference values for concentrations of GLC, 5-HMF and LA at the final reaction time: $\mathrm{GLC}=1.01 \mathrm{~g} / \mathrm{L} \mathrm{LA}=26.14 \mathrm{~g} / \mathrm{L}$, and $5-\mathrm{HMF}=0.02 \mathrm{~g} / \mathrm{L}$ (Girisuta et al. 2013). Operating conditions of simulations were: $150{ }^{\circ} \mathrm{C}, 5.2 \% \mathrm{w} / \mathrm{v}$ $\mathrm{H}_{2} \mathrm{SO}_{4}$, and $150 \mathrm{~min}$. Sensitivity calculated for the LA, GLC and 5-HMF responses in the GLN $\rightarrow$ GLC reaction reached significant ranges of variation between -9.99 and 0.73 for $E_{G L N}$ and between
-6.65 and 7.05 for $m_{G L N}$. The $A_{G L N}$ parameter showed lower sensivity values (between -1.56 and 1.85) compared to values calculated for $E_{G L N}$ and $m_{G L N}$. The $A_{G L C l}, E_{G L C l}$ and $m_{G L C l}$ parameters of the GLC $\rightarrow$ 5-HMF reaction also had significant effects on the responses according to sensitivity values calculated. The $A_{G L C 2}, E_{G L C 2}$ and $m_{G L C 2}$ parameters of the GLC $\rightarrow$ HUs reaction also had significant effects on the responses under the same premise. However, a further study of the $m_{G L C 2}$ parameter, which is directly related with the synthesis of humins (HUs) is suggested. Humins are heterogeneous polymeric compounds, consisting of several functional groups, such as for aldehydes, ketones and carboxyl groups (Sangregorio et al. 2019). A further study of the changes of these functional groups would lead to a more reliable estimation of the $m_{G L C 2}$ parameter. Parameters $A_{5-H M F}, E_{5-H M F}$ and $m_{5-H M F}$ of the 5 -HMF $\rightarrow$ LA reaction had significant effects only for the 5-HMF response. It is highlighted that the $E_{5-}$ $H M F$ parameter had a much greater effect on the 5-HMF response (near 400 times greater) when compared to effects of the $A_{5-H M F}$ and $m_{5-H M F}$ parameters. Thus, in the procedure of parameter estimation $E_{5-H M F}$ should have a narrow search range, or its value should be fixed from specialized literature. A search range of $\pm 10 \%$ or $\pm 25 \%$ of its nominal value would produce a considerable reduction of the convergence towards its optimum value, also affecting the convergence speed of the other parameters.

In this study, the parameters with relevant effects: $E_{G L N}, m_{G L N}, A_{G L C 1}, E_{G L C 1}, m_{G L C 1}, A_{G L C 2}$ and $E_{G L C 2}$, $A_{5-H M F}, m_{5-H M F}$ were considered in the parameter estimation procedure using the genetic algorithm. Based on the discussion above, the remaining parameters were set as follows (Girisuta et al. 2013): $A_{G L N}=1.12 \times 10^{5} \mathrm{~min}^{-1}, \quad E_{5-H M F}=24.42 \mathrm{~kJ} / \mathrm{mol}$ and $m_{G L C 2}=1.08$.

Results of genetic algorithm configuration

The genetic algorithm (GA) configuration procedure considered the definition of the maximum number of generations (GI) or iterations and the number of individuals in the initial population (IP) using a procedure based in a central composite design (CCD). Table 4 shows the nine scenarios defined by $\mathrm{CCD}$ and the values of performance measurements, $\mathrm{R}^{2}$ 
Table 3 Sensitivity matrix calculated for the adopteded kinetic model (Girisuta et al. 2013)

\begin{tabular}{|c|c|c|c|c|c|}
\hline \multirow[t]{2}{*}{ Reaction } & \multirow[t]{2}{*}{ Parameter } & \multirow[t]{2}{*}{ Parameter variation $(\%)$} & \multicolumn{3}{|c|}{ Sensitivity Matrix } \\
\hline & & & LA & GLC & 5-HMF \\
\hline \multirow[t]{12}{*}{ GLN $\rightarrow$ GLC } & \multirow[t]{4}{*}{$A_{G L N}\left(\min ^{-1}\right)$} & 25 & 0.14 & -1.41 & -1.41 \\
\hline & & 10 & 0.17 & -1.56 & -1.55 \\
\hline & & -10 & -0.22 & 1.75 & 1.73 \\
\hline & & -25 & -0.27 & 1.85 & 1.83 \\
\hline & \multirow[t]{4}{*}{$E_{G L N}(\mathrm{~kJ} / \mathrm{mol})$} & 25 & -4.00 & -4.00 & -4.00 \\
\hline & & 10 & -9.53 & -7.67 & -7.70 \\
\hline & & -10 & 0.73 & -9.99 & -9.99 \\
\hline & & -25 & 0.29 & -4.00 & -4.00 \\
\hline & \multirow[t]{4}{*}{$m_{G L N}$} & 25 & -1.52 & 3.96 & 3.89 \\
\hline & & 10 & -1.25 & 7.05 & 6.97 \\
\hline & & -10 & 0.57 & -6.65 & -6.62 \\
\hline & & -25 & 0.29 & -3.92 & -3.92 \\
\hline \multirow[t]{12}{*}{$\mathrm{GLC} \rightarrow 5-\mathrm{HMF}$} & \multirow[t]{4}{*}{$A_{G L C l}\left(\min ^{-1}\right)$} & 25 & 0.44 & -0.62 & 0.23 \\
\hline & & 10 & 0.47 & -0.68 & 0.25 \\
\hline & & -10 & -0.52 & 0.79 & -0.29 \\
\hline & & -25 & -0.56 & 0.89 & -0.33 \\
\hline & \multirow[t]{4}{*}{$E_{G L C l}(\mathrm{~kJ} / \mathrm{mol})$} & 25 & -4.00 & 9.02 & -4.00 \\
\hline & & 10 & -9.74 & 21.74 & -9.58 \\
\hline & & -10 & 9.24 & -9.82 & 3.60 \\
\hline & & -25 & 3.79 & -4.00 & 1.47 \\
\hline & \multirow[t]{4}{*}{$m_{G L C l}$} & 25 & -1.60 & 2.83 & -1.10 \\
\hline & & 10 & -1.59 & 2.53 & -0.95 \\
\hline & & -10 & 1.57 & -2.19 & 0.81 \\
\hline & & -25 & 1.52 & -1.94 & 0.71 \\
\hline \multirow[t]{12}{*}{ GLC $\rightarrow$ HUs } & \multirow[t]{4}{*}{$A_{G L C 2}\left(\min ^{-1}\right)$} & 25 & -0.42 & -0.57 & -0.57 \\
\hline & & 10 & -0.44 & -0.62 & -0.62 \\
\hline & & -10 & 0.48 & 0.70 & 0.70 \\
\hline & & -25 & 0.52 & 0.79 & 0.79 \\
\hline & \multirow[t]{4}{*}{$E_{G L C 2}(\mathrm{~kJ} / \mathrm{mol})$} & 25 & 3.36 & 7.03 & 7.02 \\
\hline & & 10 & 8.24 & 17.14 & 17.11 \\
\hline & & -10 & -9.78 & -9.85 & -9.85 \\
\hline & & -25 & -4.00 & -4.00 & -4.00 \\
\hline & \multirow[t]{4}{*}{$m_{G L C 2}$} & 25 & 1.35 & 2.26 & 2.26 \\
\hline & & 10 & 1.47 & 2.24 & 2.24 \\
\hline & & -10 & -1.51 & -2.03 & -2.03 \\
\hline & & -25 & -1.45 & -1.79 & -1.79 \\
\hline
\end{tabular}


Table 3 continued

\begin{tabular}{|c|c|c|c|c|c|}
\hline \multirow[t]{2}{*}{ Reaction } & \multirow[t]{2}{*}{ Parameter } & \multirow[t]{2}{*}{ Parameter variation $(\%)$} & \multicolumn{3}{|c|}{ Sensitivity Matrix } \\
\hline & & & LA & GLC & 5-HMF \\
\hline \multirow[t]{12}{*}{$5-\mathrm{HMF} \rightarrow \mathrm{LA}$} & \multirow[t]{4}{*}{$A_{5-H M F}\left(\min ^{-1}\right)$} & 25 & 0.00 & 0.00 & -0.81 \\
\hline & & 10 & 0.00 & 0.00 & -0.92 \\
\hline & & -10 & 0.00 & 0.00 & 1.12 \\
\hline & & -25 & 0.00 & 0.00 & 1.36 \\
\hline & \multirow[t]{4}{*}{$E_{5-H M F}(\mathrm{~kJ} / \mathrm{mol})$} & 25 & -3.59 & 0.00 & 3818.67 \\
\hline & & 10 & -0.21 & 0.00 & 220.66 \\
\hline & & -10 & 0.01 & 0.00 & -9.45 \\
\hline & & -25 & 0.00 & 0.00 & -4.00 \\
\hline & \multirow[t]{4}{*}{$m_{5-H M F}$} & 25 & -0.01 & 0.00 & 6.83 \\
\hline & & 10 & 0.00 & 0.00 & 4.77 \\
\hline & & -10 & 0.00 & 0.00 & -3.22 \\
\hline & & -25 & 0.00 & 0.00 & -2.50 \\
\hline
\end{tabular}

Each column describes the sensitivity of the $L A, G L C$ and 5-HMF responses regarding the variation of each kinetic parameter of the model

and RMSE, calculated to evaluate the adjustment of the model to experimental levulinic acid (LA) data from Girisuta et al. (2013). Values of $\mathrm{R}^{2}$ and RMSE were similar for GLC and 5-HMF concentrations under the different operating conditions evaluated (data not shown). These results showed that the prediction of the model using the set of parameters of scenario 8 provided, generally, the best values of performance measurements. Thus, in this study, the procedure of the GA-based parameter estimation used a $\mathrm{GI}=300$ and an $\mathrm{IP}=101$. The mutation and crossover probabilities were 0.005 and 0.85 , respectively, as suggested by Charbonneau and Knapp (2002).

Catalytic depolymerization of cellulose (stage 3) and kinetic study

A series of experiments on cellulose catalytic depolymerization present in insoluble solid residues (insoluble solid residues from sugarcane bagasse ISR $_{\mathrm{SCB}}$, rice husk, $\mathrm{ISR}_{\mathrm{RH}}$, and soybean straw, ISRss) were executed using temperatures of $150{ }^{\circ} \mathrm{C}, 170{ }^{\circ} \mathrm{C}$, $190{ }^{\circ} \mathrm{C}$ and different concentrations of $\mathrm{H}_{2} \mathrm{SO}_{4}(3.0 \%$ $\mathrm{w} / \mathrm{v}, 5.0 \% \mathrm{w} / \mathrm{v}$, and $7.0 \% \mathrm{w} / \mathrm{v})$. Under these conditions, based on the work from Fleig et al. (2018) and Lopes et al. (2017), glucose concentrations (GLC), 5-hydroxymethylfurfural (5-HMF) and levulinic acid
(LA) were measured. Figure 2 shows the performance of the catalytic depolymerization of cellulose for each condition in terms of LA yield. For all ISRs, the cellulose depolymerization conditions at $150{ }^{\circ} \mathrm{C}$ with low concentration of $\mathrm{H}_{2} \mathrm{SO}_{4}$ were unfavorable for the formation of LA; this resulted in lower yields of $12.2 \pm 0.0 \mathrm{~mol} \%, \quad 28.8 \pm 3.5 \mathrm{~mol} \% \quad$ and $25.8 \pm 1.4 \mathrm{~mol} \%$ for $\mathrm{ISR}_{\mathrm{SCB}}, \mathrm{ISR}_{\mathrm{RH}}$ and $\mathrm{ISR}_{\mathrm{SS}}$, respectively. However, LA yields were observed at $190{ }^{\circ} \mathrm{C}$ and $\mathrm{H}_{2} \mathrm{SO}_{4}$ concentration of $3.0 \%$ w/v, resulting in values of $28.6 \pm 1.0 \mathrm{~mol} \%, 61.8 \pm 0.2 \mathrm{~mol} \%$, and $55.6 \pm 0.4 \mathrm{~mol} \%$ for $\mathrm{ISR}_{\mathrm{SCB}}, \mathrm{ISR}_{\mathrm{RH}}$ and $\mathrm{ISR}_{\mathrm{SS}}$, respectively. Even greater LA yields were observed at $190{ }^{\circ} \mathrm{C}$ and $7.0 \%$ w/v $\mathrm{H}_{2} \mathrm{SO}_{4}$ concentration: $60.5 \pm 2.1 \mathrm{~mol} \%, \quad 65.2 \pm 2.9 \mathrm{~mol} \% \quad$ and $61.5 \pm 4.0 \mathrm{~mol} \%$ for $\mathrm{ISR}_{\mathrm{SCB}}, \mathrm{ISR}_{\mathrm{RH}}$ and $\mathrm{ISR}_{\mathrm{SS}}$, respectively. For $\mathrm{ISR}_{\mathrm{RH}}$ and $\mathrm{ISR}_{\mathrm{SS}}$ the increase in $\mathrm{H}_{2} \mathrm{SO}_{4}$ concentration of $3.0-7.0 \%$ w/v did not improve, significantly, the LA yield. A previous study of levulinic acid production from cellulose was executed at $180{ }^{\circ} \mathrm{C}$ and $60 \mathrm{~min}$ and could obtain $72.5 \mathrm{~mol} \%$ levulinic acid under an optimal condition in which the mass ratio of sulfolane, water and $\mathrm{H}_{2} \mathrm{SO}_{4}$ was 90:10:1 (Wang et al. 2017). The conversion of cellulose to levulinic acid was made by oxidation pretreatment combined with alcoholysis over $\mathrm{Al}_{2}(-$ $\left.\mathrm{SO}_{4}\right)_{3}$ catalyst by Zhou et al. (2020) reaching a LA yield of $66.8 \mathrm{~mol} \%$ at $180{ }^{\circ} \mathrm{C}$ for $3 \mathrm{~h}$. In the present 


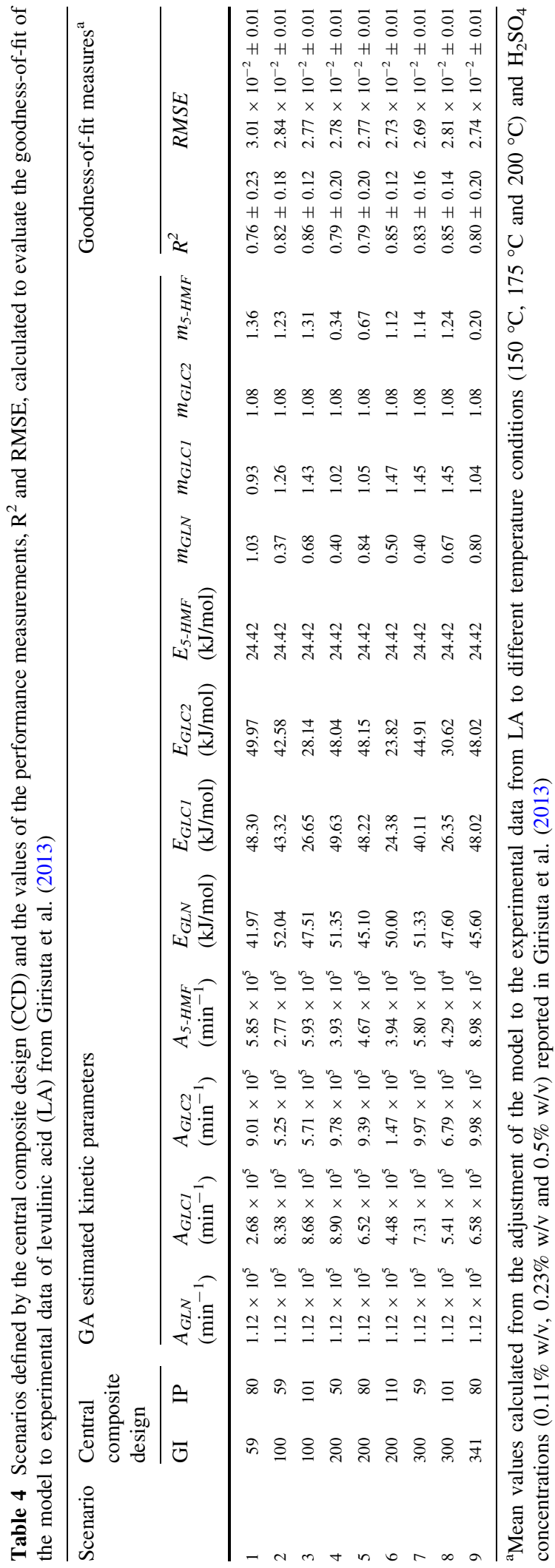




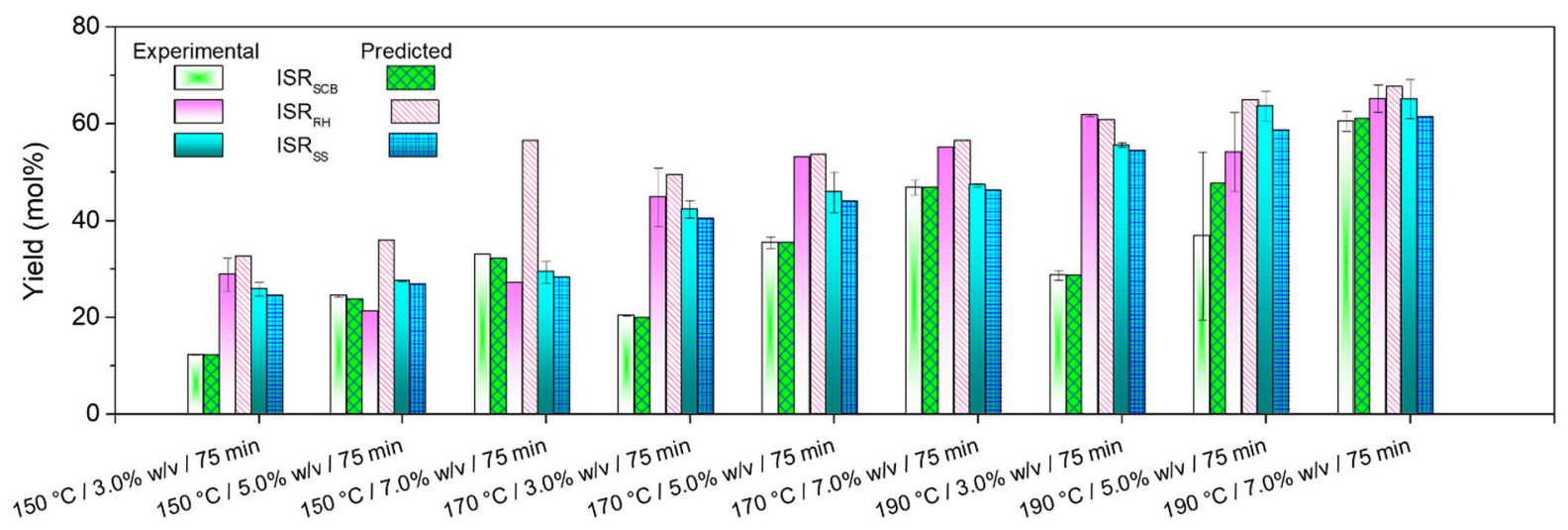

Fig. 2 Performance of the cellulose catalytic depolymerization regarding levulinic acid yield

study, a high temperature of $190{ }^{\circ} \mathrm{C}$ may have contributed to a decrease of the degree of cellulose crystallinity, leading to a higher rate of cellulose depolymerization, which, in consequence, led to higher yields. In addition, high temperatures decrease the effects of viscosity and increase the rate of mass transfer (Liu et al. 2019), possibly benefiting the depolymerization rate. The crystalline structure of cellulose is considered one of the main factors that may limit its susceptibility to the process of biorefining. In the ISR structure the hemicelluloses and lignin, are deeply interconnected in their structure, obstructing pores in amorphous and crystalline structures of cellulose. Thus, biomass components (cellulose, hemicelluloses and lignin) are linked together, mainly by hydrogen bonds, as in the case of SCB (Laluce et al. 2019). In RH the lignin and the hemicelluloses are encapsulated by the crystalline cellulose, thus the functional groups are limited, resulting in reduced $\mathrm{RH}$ chemical utilization (Xiong et al. 2019). According to Martelli-Tosi et al. (2017), SS fiber contains extremely parallel organized cellulose micro fibrils presenting particles in a well compacted configuration. In this study, crystallinity indices $(\mathrm{CrI})$ were calculated for all ISRs as shown in Table 2. Despite the degree of crystallinity observed in the ISRs, the optimum conditions used in stage 3 allowed a satisfactory cellulose depolymerization. Fleig et al. (2018) observed that the extensive delignification (Stage 2), aiming at the solubilization of ashes in ISRs also contributed to a satisfactory depolymerization.

The experimental measurements, temperatures and concentrations of $\mathrm{H}_{2} \mathrm{SO}_{4}$ were used to execute the procedure of parameter estimation based on the genetic algorithm previously described. Table 5 shows a set of optimum values of kinetic parameters $\left[A_{i}, E_{A i}\right.$ and $m_{i}$ in the Arrhenius-type Eq. (6) ] for each ISR considered. It is possible to observe that the values of activation energy $E_{G L N}$, for all ISRs were higher when compared to the values of activation energies $E_{G L C 1}, E_{G L C 2}$ and $E_{5-H M F}$. Those results suggest a greater temperature dependence on the glucose formation reaction when compared to the 5-HMF, HUs and LA formation reactions. The values calculated of parameter $E_{G L N}$ of $57.5 \mathrm{~kJ} / \mathrm{mol}, 56.1 \mathrm{~kJ} / \mathrm{mol}$ and $58.0 \mathrm{~kJ} / \mathrm{mol}$ for $\mathrm{ISR}_{\mathrm{SCB}}, \mathrm{ISR}_{\mathrm{RH}}$ and $\mathrm{ISR}_{\mathrm{SS}}$, respectively, were lower than the values reported in literature. Values of $144.8 \mathrm{~kJ} / \mathrm{mol}, 107.9 \mathrm{~kJ} / \mathrm{mol}$, $151.5 \mathrm{~kJ} / \mathrm{mol}$ and $116 \mathrm{~kJ} / \mathrm{mol}$ were estimated for sugarcane bagasse (Girisuta et al. 2013), miscanthus

Table 5 Estimated values of the kinetic parameters $\left(A_{i}, E_{A i}\right.$ and $m_{i}$ in Eq. 6), from the optimization procedure based on genetic algorithm, for each ISR considered

\begin{tabular}{llll}
\hline Kinetic parameters & ISR $_{\mathrm{SCB}}$ & ISR $_{\mathrm{RH}}$ & $\mathrm{ISR}_{\mathrm{SS}}$ \\
\hline$A_{G L N}\left(\mathrm{~min}^{-1}\right)$ & $1.12 \times 10^{5}$ & $1.12 \times 10^{5}$ & $1.12 \times 10^{5}$ \\
$A_{G L C l}\left(\mathrm{~min}^{-1}\right)$ & $4.50 \times 10^{5}$ & $5.65 \times 10^{5}$ & $5.81 \times 10^{5}$ \\
$A_{G L C 2}\left(\mathrm{~min}^{-1}\right)$ & $4.01 \times 10^{4}$ & $6.03 \times 10^{5}$ & $5.06 \times 10^{5}$ \\
$A_{5-H M F}\left(\mathrm{~min}^{-1}\right)$ & $3.18 \times 10^{5}$ & $8.80 \times 10^{5}$ & $9.38 \times 10^{5}$ \\
$E_{G L N}(\mathrm{~kJ} / \mathrm{mol})$ & 57.50 & 56.05 & 58.03 \\
$E_{G L C l}(\mathrm{~kJ} / \mathrm{mol})$ & 32.54 & 3.62 & 4.14 \\
$E_{G L C 2}(\mathrm{~kJ} / \mathrm{mol})$ & 37.60 & 6.10 & 6.03 \\
$E_{5-H M F}(\mathrm{~kJ} / \mathrm{mol})$ & 24.42 & 24.42 & 24.42 \\
$m_{G L N}$ & 0.31 & 0.12 & 0.05 \\
$m_{G L C 1}$ & 2.30 & 1.28 & 1.31 \\
$m_{G L C 2}$ & 1.08 & 1.08 & 1.08 \\
$m_{5-H M F}$ & 1.94 & 1.86 & 2.01 \\
\hline
\end{tabular}


Table 6 Reaction rate constants calculated from Arrhenius parameters optimized under different conditions of temperature and concentration of $\mathrm{H}_{2} \mathrm{SO}_{4}$

\begin{tabular}{|c|c|c|c|c|c|c|}
\hline ISR & $T\left({ }^{\circ} \mathrm{C}\right)$ & $\mathrm{H}_{2} \mathrm{SO}_{4}(\% \mathrm{w} / \mathrm{v})$ & $k_{G L N}\left(\min ^{-1}\right)$ & $k_{G L C l}\left(\min ^{-1}\right)$ & $k_{G L C 2}\left(\min ^{-1}\right)$ & $k_{5-H M F}\left(\min ^{-1}\right)$ \\
\hline \multirow[t]{9}{*}{ SCB } & \multirow[t]{3}{*}{150} & 3.0 & $3.03 \times 10^{-3}$ & $1.36 \times 10^{-2}$ & $2.07 \times 10^{-2}$ & $3.42 \times 10^{-1}$ \\
\hline & & 5.0 & $3.54 \times 10^{-3}$ & $4.41 \times 10^{-2}$ & $3.60 \times 10^{-2}$ & $9.21 \times 10^{-1}$ \\
\hline & & 7.0 & $3.93 \times 10^{-3}$ & $9.56 \times 10^{-2}$ & $5.17 \times 10^{-2}$ & 1.77 \\
\hline & \multirow[t]{3}{*}{170} & 3.0 & $6.33 \times 10^{-3}$ & $2.07 \times 10^{-2}$ & $3.36 \times 10^{-2}$ & $4.68 \times 10^{-1}$ \\
\hline & & 5.0 & $7.41 \times 10^{-3}$ & $6.69 \times 10^{-2}$ & $5.83 \times 10^{-2}$ & 1.26 \\
\hline & & 7.0 & $8.22 \times 10^{-3}$ & $1.45 \times 10^{-1}$ & $8.38 \times 10^{-2}$ & 2.42 \\
\hline & \multirow[t]{3}{*}{190} & 3.0 & $1.24 \times 10^{-2}$ & $3.03 \times 10^{-2}$ & $5.22 \times 10^{-2}$ & $6.22 \times 10^{-1}$ \\
\hline & & 5.0 & $1.45 \times 10^{-2}$ & $9.80 \times 10^{-2}$ & $9.05 \times 10^{-2}$ & 1.68 \\
\hline & & 7.0 & $1.61 \times 10^{-2}$ & $2.13 \times 10^{-1}$ & $1.30 \times 10^{-1}$ & 3.22 \\
\hline \multirow[t]{9}{*}{ RH } & \multirow[t]{3}{*}{150} & 3.0 & $8.84 \times 10^{-3}$ & 2277.74 & 2412.00 & 1.25 \\
\hline & & 5.0 & $9.40 \times 10^{-3}$ & 4377.20 & 4187.69 & 3.23 \\
\hline & & 7.0 & $9.79 \times 10^{-3}$ & 6730.69 & 6022.72 & 6.04 \\
\hline & \multirow[t]{3}{*}{170} & 3.0 & $1.82 \times 10^{-2}$ & 2386.13 & 2608.39 & 1.71 \\
\hline & & 5.0 & $1.93 \times 10^{-2}$ & 4585.50 & 4528.65 & 4.42 \\
\hline & & 7.0 & $2.01 \times 10^{-2}$ & 7050.99 & 6513.09 & 8.26 \\
\hline & \multirow[t]{3}{*}{190} & 3.0 & $3.50 \times 10^{-2}$ & 2489.66 & 2801.75 & 2.27 \\
\hline & & 5.0 & $3.72 \times 10^{-2}$ & 4784.46 & 4864.37 & 5.88 \\
\hline & & 7.0 & $3.88 \times 10^{-2}$ & 7356.93 & 6995.92 & 11.00 \\
\hline \multirow[t]{9}{*}{ SS } & \multirow[t]{3}{*}{150} & 3.0 & $6.40 \times 10^{-3}$ & 1786.99 & 2064.46 & 0.79 \\
\hline & & 5.0 & $6.57 \times 10^{-3}$ & 3496.72 & 3584.29 & 2.20 \\
\hline & & 7.0 & $6.69 \times 10^{-3}$ & 5441.16 & 5154.92 & 4.33 \\
\hline & \multirow[t]{3}{*}{170} & 3.0 & $1.35 \times 10^{-2}$ & 1884.46 & 2230.58 & 1.08 \\
\hline & & 5.0 & $1.38 \times 10^{-2}$ & 3687.45 & 3872.71 & 3.01 \\
\hline & & 7.0 & $1.41 \times 10^{-2}$ & 5737.95 & 5569.72 & 5.92 \\
\hline & \multirow[t]{3}{*}{190} & 3.0 & $2.66 \times 10^{-2}$ & 1978.16 & 2394.02 & 1.44 \\
\hline & & 5.0 & $2.73 \times 10^{-2}$ & 3870.78 & 4156.47 & 4.01 \\
\hline & & 7.0 & $2.78 \times 10^{-2}$ & 6023.24 & 5977.82 & 7.88 \\
\hline
\end{tabular}

(Dussan et al. 2013), cellulose (Girisuta et al. 2007) and corncob residues (Wang et al. 2019), respectively. Notwithstanding, a wide range of $E_{A}$ has been reported in literature (Table 1), which can be attributed, at least in part, to the variety of catalyst systems and solvents being used. An important factor that alters the values of $E_{A}$ of the different reactions is the difference in the heating profile regarding the distinct heating modes that exist (oil bath, electric resistance and others) (Mukherjee and Dumont 2016). In this study it was also explicitly demonstrated the influence of the $\mathrm{H}_{2} \mathrm{SO}_{4}$ concentration on the kinetic behavior of cellulose catalytic depolymerization. Very low values (close to zero for all ISRs) for parameter $m_{G L N}$ (reaction order for $\mathrm{H}_{2} \mathrm{SO}_{4}$ concentration), were reported regarding the values for $m_{G L C 1}, m_{G L C 2}$ and $m_{5-H M F}$. Those results suggest that the GLC formation reaction was poorly sensitive to the $\mathrm{H}_{2} \mathrm{SO}_{4}$ concentration when compared to 5-HMF, HUs and LA formation reactions.

The optimal values of the Arrhenius parameters were used to calculate the reaction rates constants $\left(k_{G L}, k_{G L C 1}, k_{G L C 2}\right.$ and $\left.k_{H M F}\right)$ shown in Table 6. These data clearly demonstrate the influence of temperature and $\mathrm{H}_{2} \mathrm{SO}_{4}$ concentration on reaction rate constants. For all ISRs, as the temperature rose from 150 to $190{ }^{\circ} \mathrm{C}$ and the concentration of $\mathrm{H}_{2} \mathrm{SO}_{4}$ from 3.0 to $7.0 \% \mathrm{w} / \mathrm{v}$, reaction rate constants values increased by different proportions. Previous studies (Girisuta et al. 2006, 2007, 2013), corroborate the significant effect of 

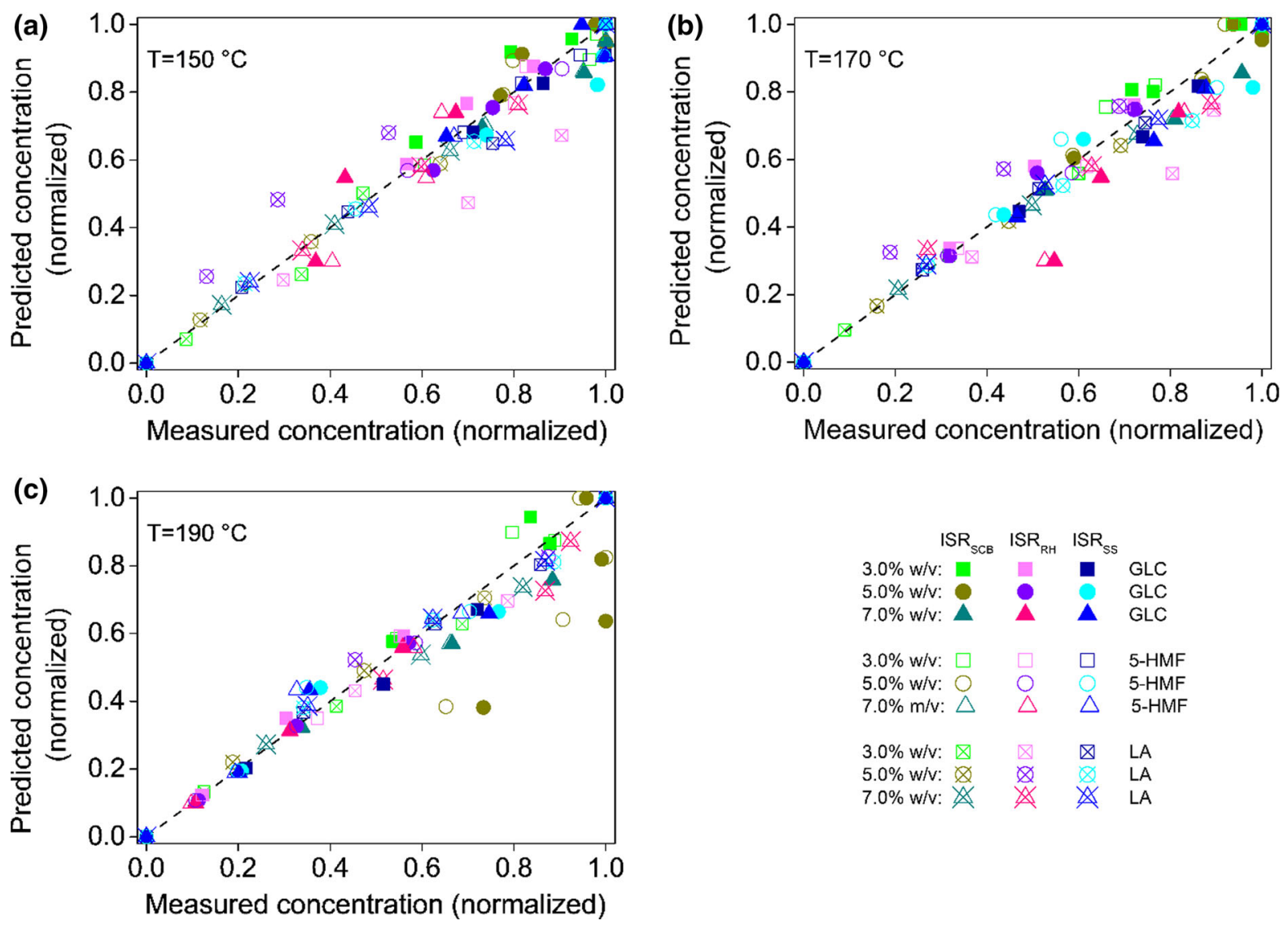

Fig. 3 Predicted versus measured values for concentrations (normalized) of GLC, 5-HMF and LA during cellulose depolymerization (for all ISRs) and concentrations estimated by the mechanistic model (Eqs. 1-5)

temperature and $\mathrm{H}_{2} \mathrm{SO}_{4}$ concentration on the kinetics of catalytic cellulose depolymerization. For $\mathrm{ISR}_{\mathrm{SCB}}$, considering a fixed temperature, the increase of $\mathrm{H}_{2} \mathrm{SO}_{4}$ concentration produced a significant variation around $85 \%, 60 \%$ and $82 \%$ for constants $k_{G L C 1}, k_{G L C 2}$ and $k_{5-}$ $H M F$ respectively. A smaller variation, around $23 \%$, was produced for constant $k_{G L N}$. Similarly, for ISR SCB $_{\mathrm{SC}}$ and ISR $_{\mathrm{SS}}$, minor variations of around $9 \%$ and $4 \%$ respectively, were observed for constant $k_{G L N}$, while variations for constants $k_{G L C 1}, k_{5-H M F}$ and $k_{G L C 2}$ were over $60 \%$. Results suggest that, for all ISRs, the HUs, 5-HMF and LA formation rates increase considerably at high concentrations of $\mathrm{H}_{2} \mathrm{SO}_{4}$, when compared to the formation rate of GLC. Thus, it is observed that the formation of GLC could be considered the limiting stage of the cellulose catalytic depolymerization process when considering the variation of $\mathrm{H}_{2} \mathrm{SO}_{4}$ concentration. Previous studies have already demonstrated that the rehydration of 5-HMF in acidic medium leading to the formation of LA is not a limiting stage of the process (Chang et al. 2006; Girisuta et al. 2013; Rivas et al. 2014; Ren et al. 2015). For ISR $_{\mathrm{SCB}}$, considering a fixed concentration of $\mathrm{H}_{2} \mathrm{SO}_{4}$, the temperature increase produced a variation of around $75 \%, 55 \%, 60 \%$ and $45 \%$ for constants $k_{G L N}$, $k_{G L C 1}, k_{G L C 2}$ and $k_{5-H M F}$, respectively. Results suggest that for ISR $_{\mathrm{SCB}}$, the rate of GLC formation increases considerably with temperature. It is also observed a smaller, however significant effect, of temperature on the formation rates of HUs, 5-HMF and LA. Zhi et al. (2015) pointed out that relatively high temperatures and $\mathrm{H}_{2} \mathrm{SO}_{4}$ concentrations favor the formation of LA. The low variations in constants $k_{G L C 1}, k_{G L C 2}$, for $\mathrm{ISR}_{\mathrm{RH}}$ and $\mathrm{ISR}_{\mathrm{SS}}$, suggest that the formation of HUs and 5-HMF are limiting stages of the process, when the variation of temperature is considered. Thus, there is evidence that the formation of LA is not a limiting stage, it would become limiting if the formation of 

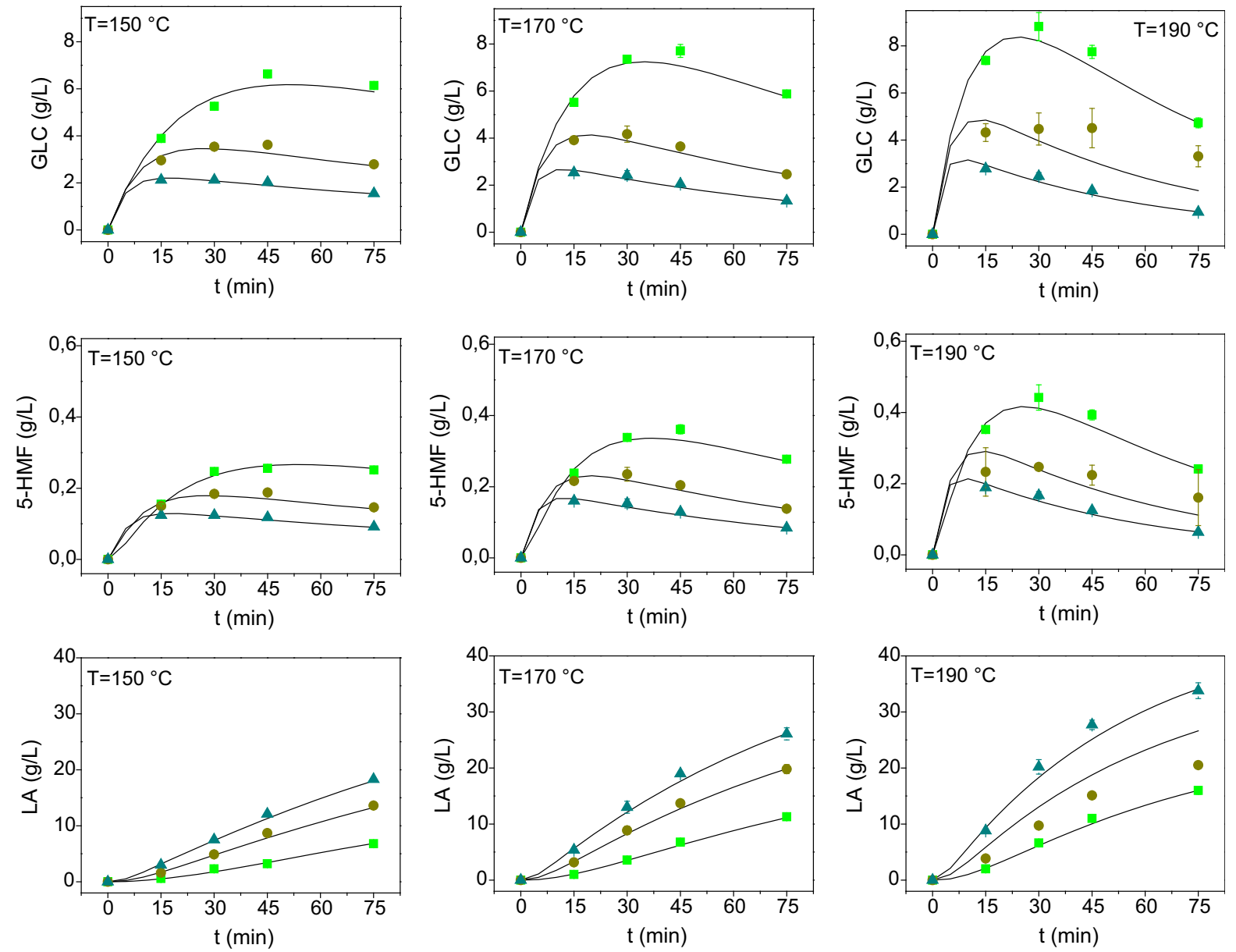

Fig. 4 Experimental measurements of glucose (GLC), 5-hidroximetilfurfural (5-HMF) and levulinic acid (LA) during the catalytic depolymerization of cellulose present in ISR $_{\mathrm{SCB}}$ compared to the simulated concentration curves (-). The experiments were made using temperatures of $150{ }^{\circ} \mathrm{C}, 170{ }^{\circ} \mathrm{C}$,

5-HMF is temperature-limited, since LA is formed from the rehydration of 5-HMF.

Figure 3 shows the graph of predicted versus observed values for measured concentrations (normalized) of GLC, 5-HMF and LA during cellulose depolymerization (for all ISRs) and the concentrations estimated by the mechanistic model (Eqs. 1-5). Results showed that the model has a good adjustment of the measured data. As an example of the predicted dynamic behavior, Fig. 4 illustrates how the model effectively tracks the desired trajectory of the data measured during the catalytic depolymerization of cellulose present in ISR $_{\mathrm{SCB}}$. Therefore, a satisfactory concordance was reached between the high yields of levulinic acid calculated by the model and the
$190{ }^{\circ} \mathrm{C}$ and different concentrations of $\mathrm{H}_{2} \mathrm{SO}_{4}$ (light green square $-3.0 \% \mathrm{w} / \mathrm{v}$, dark green circle $-5.0 \% \mathrm{w} / \mathrm{v}$, and greenishblue triangle $-7.0 \% \mathrm{w} / \mathrm{v})$. The bars represent the standard deviation of the mean

experimental yields, as shown in Fig. 2. A more rigorous quality evaluation of the adjustment between the data measured and the estimated data was made using the performance measurements $\mathrm{R}^{2}$ and RMSE. Table 7 shows that model predictions were particularly accurate as determined by the performance measurements.

Model validation was made using experimental measurements, different from those used for estimating the parameters of the model. Experimental data were generated for two conditions: (1) $160{ }^{\circ} \mathrm{C}, 4.5 \%$ $\mathrm{w} / \mathrm{v}, 5.2 \% \mathrm{w} / \mathrm{v}$ and $6.5 \% \mathrm{w} / \mathrm{v}$ of $\mathrm{H}_{2} \mathrm{SO}_{4}, 45 \mathrm{~min}$ and (2) $180{ }^{\circ} \mathrm{C}, 5.0 \% \mathrm{w} / \mathrm{v}$ of $\mathrm{H}_{2} \mathrm{SO}_{4}, 45 \mathrm{~min}$. Table 8 shows that the model had a good accuracy when compared to the validation data with an average relative error 
Table $7 \mathrm{R}^{2}$ and RMSE to evaluate the goodness-of-fit the model to experimental data of the cellulose catalytic depolymerization process present in $\mathrm{ISR}_{\mathrm{SCB}}, \mathrm{ISR}_{\mathrm{RH}}$ and ISR $\mathrm{SS}$ under different temperatures and concentrations of $\mathrm{H}_{2} \mathrm{SO}_{4}$

\begin{tabular}{|c|c|c|c|c|c|c|c|c|c|c|c|}
\hline \multirow[t]{2}{*}{$T\left({ }^{\circ} \mathrm{C}\right)$} & \multirow{2}{*}{$\begin{array}{l}\mathrm{H}_{2} \mathrm{SO}_{4} \text { concentration } \\
(\% \mathrm{w} / \mathrm{v})\end{array}$} & \multirow{2}{*}{$\begin{array}{l}\text { Goodness-of-fit } \\
\text { measures }\end{array}$} & \multicolumn{3}{|c|}{ ISR $_{\mathrm{SCB}}$} & \multicolumn{3}{|l|}{$\mathrm{ISR}_{\mathrm{RH}}$} & \multicolumn{3}{|l|}{$\mathrm{ISR}_{\mathrm{SS}}$} \\
\hline & & & GLC & 5-HMF & LA & GLC & 5-HMF & LA & GLC & 5-HMF & LA \\
\hline \multirow[t]{6}{*}{150} & \multirow[t]{2}{*}{3.0} & $\mathrm{R}^{2}$ & 0.992 & 0.998 & 0.995 & 0.995 & 0.994 & 0.924 & 0.994 & 0.998 & 0.986 \\
\hline & & RMSE & 0.305 & 0.006 & 0.253 & 0.000 & 0.008 & 1.476 & 0.000 & 0.005 & 0.974 \\
\hline & \multirow[t]{2}{*}{5.0} & $\mathrm{R}^{2}$ & 0.991 & 0.992 & 0.998 & 0.996 & 0.999 & 0.947 & 0.979 & 0.979 & 0.995 \\
\hline & & RMSE & 0.190 & 0.010 & 0.426 & 0.000 & 0.028 & 4.812 & 0.000 & 0.006 & 0.566 \\
\hline & \multirow[t]{2}{*}{7.0} & $\mathrm{R}^{2}$ & 0.996 & 0.997 & 0.999 & 0.967 & 0.962 & 0.998 & 0.982 & 0.991 & 0.983 \\
\hline & & RMSE & 0.072 & 0.004 & 0.381 & 0.000 & 0.008 & 8.275 & 0.000 & 0.002 & 1.154 \\
\hline \multirow[t]{6}{*}{170} & \multirow[t]{2}{*}{3.0} & $\mathrm{R}^{2}$ & 0.995 & 0.995 & 0.999 & 0.993 & 0.991 & 0.938 & 0.994 & 0.994 & 0.998 \\
\hline & & RMSE & 0.326 & 0.015 & 0.262 & 0.000 & 0.011 & 2.046 & 0.000 & 0.013 & 0.893 \\
\hline & \multirow[t]{2}{*}{5.0} & $\mathrm{R}^{2}$ & 0.994 & 0.993 & 0.998 & 0.996 & 0.998 & 0.971 & 0.963 & 0.973 & 0.981 \\
\hline & & RMSE & 0.190 & 0.011 & 0.509 & 0.000 & 0.003 & 2.309 & 0.000 & 0.009 & 2.057 \\
\hline & \multirow[t]{2}{*}{7.0} & $\mathrm{R}^{2}$ & 0.994 & 0.994 & 0.998 & 0.931 & 0.942 & 0.977 & 0.987 & 0.987 & 0.996 \\
\hline & & RMSE & 0.111 & 0.007 & 0.727 & 0.000 & 0.013 & 1.484 & 0.000 & 0.003 & 0.917 \\
\hline \multirow[t]{6}{*}{190} & \multirow[t]{2}{*}{3.0} & $\mathrm{R}^{2}$ & 0.993 & 0.993 & 0.998 & 0.997 & 0.997 & 0.991 & 0.994 & 0.994 & 0.996 \\
\hline & & RMSE & 0.426 & 0.022 & 0.471 & 0.000 & 0.010 & 1.463 & 0.000 & 0.013 & 1.913 \\
\hline & \multirow[t]{2}{*}{5.0} & $\mathrm{R}^{2}$ & 0.895 & 0.931 & 0.999 & 1.000 & 1.000 & 0.989 & 0.980 & 0.985 & 0.987 \\
\hline & & RMSE & 0.969 & 0.038 & 3.643 & 0.000 & 0.002 & 4.315 & 0.000 & 0.008 & 2.578 \\
\hline & \multirow[t]{2}{*}{7.0} & $\mathrm{R}^{2}$ & 0.990 & 0.991 & 0.995 & 1.000 & 0.999 & 0.981 & 0.980 & 0.983 & 0.994 \\
\hline & & RMSE & 0.149 & 0.010 & 1.444 & 0.000 & 0.001 & 1.649 & 0.000 & 0.050 & 1.913 \\
\hline
\end{tabular}

$\left(\varepsilon_{\text {relative }}\right)$ of $11 \%$. Those results demonstrate that the model can be used to predict the dynamic behavior of the cellulose catalytic depolymerization process, present in $\mathrm{ISR}_{\mathrm{SCB}}$, ISR $\mathrm{ISH}_{\mathrm{RH}}$, ISR $\mathrm{SS}$, under the current conditions. Thus, the kinetic model incorporating temperature and $\mathrm{H}_{2} \mathrm{SO}_{4}$ concentration dependence functions can be used to predict the concentrations of GLC, 5-HMF and LA during the change of temperature in the reaction, as well as with different concentrations of $\mathrm{H}_{2} \mathrm{SO}_{4}$. The model can deal with temperature fluctuations between 150 and $190{ }^{\circ} \mathrm{C}$, and with $\mathrm{H}_{2} \mathrm{SO}_{4}$ concentrations between 3.0 and $7.0 \%$ w/v.

The proposed mechanistic model could provide the base for the synthesis, design and operation of the process of levulinic acid production from agro-industrial waste. In recent years, the agro-industry segment has been constantly witnessing the increase of competitiveness, concomitantly with the increase of its waste. Thus, it is also necessary to adopt new technologies and strategies from the point of view of process synthesis and design, for the production of levulinic acid.

Process synthesis and design for producing levulinic acid from agro-industrial waste

Considering the strategy from the point of view of process synthesis and design, a mass balance for the production of levulinic acid (LA) from $100 \mathrm{~kg}$ (on a dry basis) of each agro-industrial waste (sugarcane bagasse, SCB, rice rusk, RH and soybean straw, SS) was prepared. The mass balance of the process of biorefining in three stages was made using the optimum conditions for the third stage $\left(190{ }^{\circ} \mathrm{C}\right.$, $7.0 \% \mathrm{w} / \mathrm{v}$ of $\mathrm{H}_{2} \mathrm{SO}_{4}$ and $75 \mathrm{~min}$ ). Overall conversion yields of initial cellulose (integral lignocellulosic material) into LA were of $39.2 \pm 1.3 \% \quad(39.6 \%$ predicted by the model), $33.2 \pm 1.5 \%$ (34.5\% predicted) and $40.3 \pm 2.5 \%$ (38.0\% predicted) for SCB, $\mathrm{RH}$ and SS, respectively. Considering the estimated global yields, LA production was of $15.9 \mathrm{~kg}(16.0 \mathrm{~kg}$ 
Table 8 Relative error $\left(\varepsilon_{\text {relative }}\right)$ to evaluate the adjustment of the model to the experimental data ( \pm standard deviation of three independent experiments), for validating the process of cellulose catalytic depolymerization present in $\mathrm{ISR}_{\mathrm{SCB}}$, and ISR $_{\text {SS }}$ under different operating conditions

\begin{tabular}{|c|c|c|c|c|c|c|c|c|c|}
\hline \multirow{3}{*}{$\begin{array}{l}\mathrm{T} \\
\left({ }^{\circ} \mathrm{C}\right)\end{array}$} & \multirow{3}{*}{$\begin{array}{l}\mathrm{H}_{2} \mathrm{SO}_{4} \text { concentration } \\
(\% \mathrm{w} / \mathrm{v})\end{array}$} & \multicolumn{8}{|c|}{ ISRs from the RH e SS biomass } \\
\hline & & \multicolumn{4}{|l|}{$\mathrm{ISR}_{\mathrm{RH}}$} & \multicolumn{4}{|l|}{$\mathrm{ISR}_{\mathrm{SS}}$} \\
\hline & & 5-HMF (g/L) & $\begin{array}{l}\varepsilon_{\text {relative }} \\
(\%)\end{array}$ & $\mathrm{LA}(\mathrm{g} / \mathrm{L})$ & $\begin{array}{l}\varepsilon_{\text {relative }} \\
(\%)\end{array}$ & 5-HMF (g/L) & $\begin{array}{l}\varepsilon_{\text {relative }} \\
(\%)\end{array}$ & $\mathrm{LA}(\mathrm{g} / \mathrm{L})$ & $\begin{array}{l}\varepsilon_{\text {relative }} \\
(\%)\end{array}$ \\
\hline 165 & 4.5 & $\begin{array}{l}7.1 \times 10^{-2} \\
( \pm 0.0) \\
{\left[7.3 \times 10^{-2}\right]}\end{array}$ & 2.2 & $\begin{array}{l}17.2 \\
\quad( \pm 0.9) \\
{[16.1]}\end{array}$ & 6.4 & $\begin{array}{l}1.5 \times 10^{-1} \\
( \pm 0.0) \\
{\left[1.1 \times 10^{-1}\right]}\end{array}$ & 23.3 & $\begin{array}{l}16.8 \\
\quad( \pm 1.9) \\
{[15.1]}\end{array}$ & 10.4 \\
\hline & 5.2 & $\begin{array}{l}5.1 \times 10^{-2} \\
( \pm 0.0) \\
{\left[5.7 \times 10^{-2}\right]}\end{array}$ & 10.9 & $\begin{array}{l}17.3 \\
\quad( \pm 0.8) \\
{[16.5]}\end{array}$ & 4.4 & $\begin{array}{l}8.5 \times 10^{-2} \\
( \pm 0.0) \\
{\left[8.8 \times 10^{-2}\right]}\end{array}$ & 3.5 & $\begin{array}{l}18.0 \\
\quad( \pm 2.3) \\
{[15.5]}\end{array}$ & 13.8 \\
\hline & 6.5 & $\begin{array}{l}3.4 \times 10^{-2} \\
\quad( \pm 0.0) \\
{\left[3.9 \times 10^{-2}\right]}\end{array}$ & 12.1 & $\begin{array}{l}20.3 \\
\quad( \pm 0.0) \\
{[17.2]}\end{array}$ & 15.2 & $\begin{array}{l}5.9 \times 10^{-2} \\
( \pm 0.0) \\
{\left[5.8 \times 10^{-2}\right]}\end{array}$ & 2.2 & $\begin{array}{l}15.0 \\
( \pm 0.9) \\
{[16.1]}\end{array}$ & 7.4 \\
\hline 180 & 6.5 & $\begin{array}{l}2.9 \times 10^{-2} \\
\quad( \pm 0.0) \\
{\left[3.1 \times 10^{-2}\right]}\end{array}$ & 5.6 & $\begin{array}{l}19.9 \\
\quad( \pm 1.6) \\
{[23.0]}\end{array}$ & 15.5 & $\begin{array}{l}4.1 \times 10^{-2} \\
( \pm 0.0) \\
{\left[5.4 \times 10^{-2}\right]}\end{array}$ & 30.0 & $\begin{array}{l}27.0 \\
\quad( \pm 1.4) \\
{[23.0]}\end{array}$ & 14.8 \\
\hline
\end{tabular}

The numbers in brackets are the values predicted by the model

predicted), $12.8 \mathrm{~kg}$ (13.2 kg predicted) and $16.2 \mathrm{~kg}$ (15.2 $\mathrm{kg}$ predicted) $\mathrm{SCB}, \mathrm{RH}$ and $\mathrm{SS}$, respectively, as observed in Fig. 5. Thus, different amounts of cellulose, hemicelluloses and lignin may indicate different trends in decomposition and, consequently, in the formation of LA, due to their difference regarding structural characteristics such as crystallinity and cross linking. Ozsel et al. (2019) evaluated the conversion of three different biomasses and found that the structural properties of the raw material are an important question. After hydrolyzes $(3 \mathrm{~h})$ at $200{ }^{\circ} \mathrm{C}$ and in the presence of the catalyst (concentrated $\left.\mathrm{H}_{2} \mathrm{SO}_{4}\right) 61.0 \%, 27.4 \%$ and $43.3 \%$ of yield were obtained for corn straw, cotton fibers and waste fluff, respectively. The highest yields of 5-HMF and LA were obtained from corn straw, proving that there is a great disparity among results, when different lignocellulosic raw materials are analyzed.

The three scenarios addressed in this study have potential to cover the yearly production of LA. The sugarcane crop in the Center-South region of Brazil usually occurs between the months of April to November (NovaCana 2019). The peak in the rice harvest occurs between the months of January to June, and of soybeans from January until May of each year
(Conab 2019). Thus, using the agro-industrial waste of these productions, it is possible to supply the offseason, pre-harvest period, of each one using the other, thus maintaining the continuity in their demands (Fig. 5). Consequently, the supply of raw materials is guaranteed to the biorefineries. In this way, the supply of products coming from LA that are so important in several areas (such as biofuel, pharmaceutical compounds, food flavoring agents and textile dyes, among others) can go on uninterrupted, thus propelling the growth and adding value to new products of biorefineries.

LA has been seen as powerful for the cost-effective production of bio-based chemicals and materials. In addition, this production has low impact of greenhouse gases and of carbon dioxide emissions. Considering this, LA brings great opportunities for the growth of a very attractive business. The estimated production for the year of 2029 for LA-derived plasticizers has a market volume of 12,000 kton per year, equivalent to a market value of 15 billion dollars. For polyamide intermediates the estimated market volume is of 14,000 kton per year with a market value of 25 billion dollars. For solvents, the market volume is estimated in 26,500 kton per year with a market value of 25 


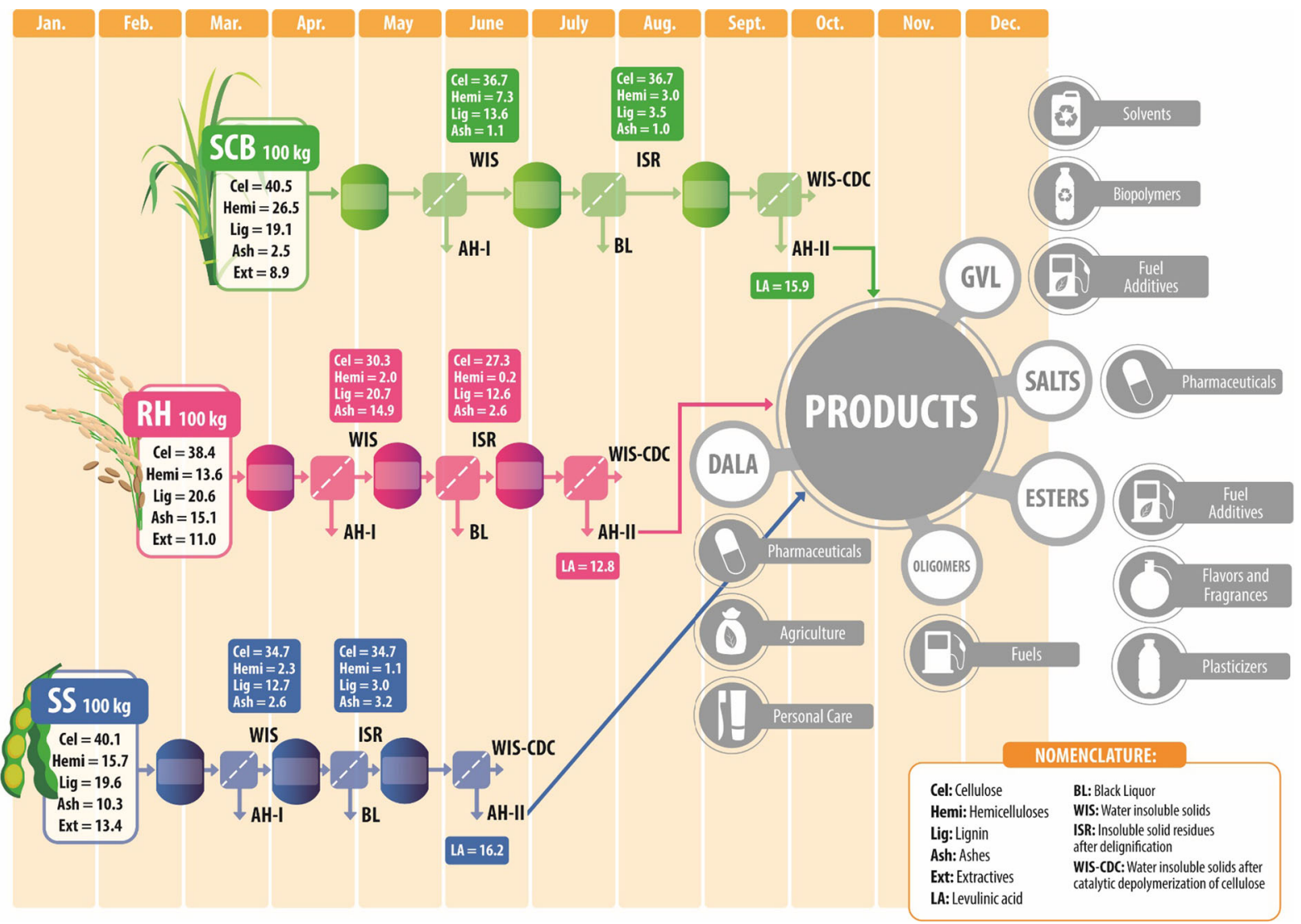

Fig. 5 Panorama of an annual calendar for the process synthesis and design of the LA production from SCB, RH and SS (values on dry basis)

billion dollars. Biofuels are a large market, with a market volume estimated in 1,600,000 kton per year and a market value of 1000 billion dollars (DSM 2019). Thus, by integrating those three biomasses: $\mathrm{SCB}, \mathrm{RH}$ and SS, it is possible to map the synergies existing between them (integrated model, product portfolios), and to adopt a production of LA with no seasonal pattern. Finally, it can be said that everything exposed in this work contributes to the definition of optimal conditions and strategies, from the point of view of the process synthesis and design for the production of LA in view of the maturation of this prominent platform.

\section{Conclusions}

The estimation of kinetic parameters of the process of levulinic acid production using mathematical models, naturally leads to a problem of non-linear optimization that is very difficult to solve. The operating conditions (temperature and $\mathrm{H}_{2} \mathrm{SO}_{4}$ concentration) must be considered in the model, to effectively explain their effects on the process kinetics. This study proposes a systemic methodology for the accurate and efficient estimation of kinetic parameters in the production process of levulinic acids from agro-industrial waste (sugarcane bagasse, SCB, rice rusk, RH and soybean straw, SS). This method combines experimental measurements of the levulinic acid (LA) production, a mechanistic model, a sensitivity analysis of model parameters and an optimizing process based on a genetic algorithm. The production of LA from SCB, RH and SS followed the three-stages biorefining methodology (Fleig et al. 2018). Despite the degree of crystallinity of cellulose, the adequate operating conditions $\left(190{ }^{\circ} \mathrm{C}, 7.0 \% \mathrm{w} / \mathrm{v}\right.$ of $\left.\mathrm{H}_{2} \mathrm{SO}_{4}, 75 \mathrm{~min}\right)$ in the third stage produced relatively high yields up to $60.5 \pm 2.1 \mathrm{~mol} \%, \quad 65.2 \pm 2.9 \mathrm{~mol} \% \quad$ and $61.5 \pm 4.0 \mathrm{~mol} \%$ for SCB, RH and SS, respectively. 
Experimental data from the third stage, under different operating conditions (at temperatures from 150 to $190{ }^{\circ} \mathrm{C}$ and aqueous $\mathrm{H}_{2} \mathrm{SO}_{4}$ solution at concentrations of $3.0 \% \mathrm{w} / \mathrm{v}, 5.0 \% \mathrm{w} / \mathrm{v}$ and $7.0 \% \mathrm{w} / \mathrm{v}$ and), were used to estimate the kinetics parameters using the systematic model-based approach. Values of the most relevant parameters (determined by sensitivity analysis) were estimated, considering different operating conditions, within an optimization framework that used a genetic algorithm to describe the highly complex reaction system. Model predictions incorporating the estimated parameters were shown in good concordance with experimental levulinic acid yields. Experimental results demonstrated that the insoluble solid residues from the biorefining of $\mathrm{RH}$ and $\mathrm{SS}\left(\mathrm{ISR}_{\mathrm{RH}}\right.$ and $\mathrm{ISR}_{\mathrm{SS}}$, respectively) are also suitable for the synthesis of levulinic acid, at temperatures between 170 and $190{ }^{\circ} \mathrm{C}$. Estimated yields (experimentally or by model) allowed to propose a process design integrating the studied agro-industrial waste to supply its off-season and, thus, ensuring the uninterrupted supply of raw materials in the production of levulinic acid.

Acknowledgments This work was supported by São Paulo Research Foundation-FAPESP (Grant Numbers 2015/175923, 2015/20630-4 and 2017/23335-9) and National Council for Scientific and Technological Development-CNPq (Public investment by Universal Call MCTIC/CNPq n. ${ }^{\circ}$ 28/2018 and Grant Number 408149/2018-3) and Fundo de incentivo à Pesquisa, Universidade Federal de Santa Maria_FIPE [2017].

\footnotetext{
Author's contribution Emília Savioli Lopes: Conceptualization, methodology, investigation (sugarcane bagasse), validation, formal analysis, data curation, writingoriginal draft; Elmer Ccopa Rivera: Writing-original draft, writing-reviewing and editing, formal analysis, visualization; Julio César de Jesus Gariboti: Conceptualization, methodology, investigation (soybean straw), validation (soybean straw), formal analysis, data curation, writing - original draft; Luis Henrique Zimmermann Feistel: Conceptualization, methodology, investigation (rice husk), validation (rice husk), formal analysis, data curation, writing - original draft; João Vitor Dutra: Conceptualization, methodology, investigation (rice husk), validation (rice husk), formal analysis, data curation, writing-original draft; Rubens Maciel Filho: Conceptualization, validation, resources, writing-reviewing and editing, resources, supervision, project administration, funding acquisition; Laura Plazas Tovar: Conceptualization, validation (rice husk and soybean straw), writing-original draft, writing-reviewing and editing, resources, visualization, formal analysis, supervision, funding acquisition.
}

\section{References}

Chang C, Ma X, Cen P (2006) Kinetics of levulinic acid formation from glucose decomposition at high temperature. Chin J Chem Eng 14:708-712. https://doi.org/10.1016/ S1004-9541(06)60139-0

Charbonneau P, Knapp B (2002) High altitude observatoryPIKAIA. https://www.hao.ucar.edu/modeling/pikaia/ pikaia.php\#sec2. Accessed 20 Aug 2019

Conab (2019) Calendário de Plantio e Colheita de Grãos no Brasil. https://www.conab.gov.br/institucional/ publicacoes/outras-publicacoes/item/7694-calendarioagricola-plantio-e-colheita. Accessed 26 June 2019

Darkwah K, Knutson BL, Seay JR (2018) A perspective on challenges and prospects for applying process systems engineering tools to fermentation-based biorefineries. ACS Sustain Chem Eng 6:2829-2844. https://doi.org/10.1021/ acssuschemeng.7b03762

Das S, Bhattacharya A, Ganguly A, Gu S, Chatterjee PK (2014) Kinetics and genetic algorithm study of acid catalysed hydrolysis of water hyacinth biomass. J Renew Sustain Energy 6:063115. https://doi.org/10.1063/1.4904723

Ding Y, Zhang W, Yu L, Lu K (2019) The accuracy and efficiency of GA and PSO optimization schemes on estimating reaction kinetic parameters of biomass pyrolysis. Energy 176:582-588. https://doi.org/10.1016/j.energy.2019.04. 030

DSM (2019) Valorizing levulinic acid tree DSM's enabling technology. http://www.biobasedgarden.nl/wp-content/ uploads/2016/12/Levulinic-Acid-Platform-9-Mar-16DSM.pdf. Accessed 16 July 2019

Dussan K, Girisuta B, Haverty D, Leahy JJ, Hayes MHB (2013) Kinetics of levulinic acid and furfural production from Miscanthus $\times$ giganteus. Bioresour Technol 149:216-224. https://doi.org/10.1016/j.biortech.2013.09. 006

Fachri BA, Abdilla RM, De BovenkampHHV, Rasrendra CB, Heeres HJ (2015) Experimental and kinetic modeling studies on the sulfuric acid catalyzed conversion of Dfructose to 5-hydroxymethylfurfural and levulinic acid in water. ACS Sustain Chem Eng 3:3024-3034. https://doi. org/10.1021/acssuschemeng.5b00023

Fleig OP, Lopes ES, Rivera EC, Maciel Filho R, Tovar LP (2018) Concept of rice husk biorefining for levulinic acid production integrating three steps: multi-response optimization, new perceptions and limitations. Process Biochem 65:146-156. https://doi.org/10.1016/j.procbio.2017. 11.015

Garcés D, Faba L, Díaz E, Ordóñez S (2019) Aqueous-phase transformation of glucose into hydroxymethylfurfural and levulinic acid by combining homogeneous and heterogeneous catalysis. Chemsuschem 12:924-934. https://doi. org/10.1002/cssc. 201802315

Girisuta B, Janssen LPBM, Heeres HJ (2006) A kinetic study on the conversion of glucose to levulinic acid. Chem Eng Res Des 84:339-349. https://doi.org/10.1205/cherd05038

Girisuta B, Janssen LPBM, Heeres HJ (2007) Kinetic study on the acid-catalyzed hydrolysis of cellulose to levulinic acid. Ind Eng Chem Res 46:1696-1708. https://doi.org/10.1021/ ie061186z 
Girisuta B, Dussan K, Haverty D, Leahy J, Hayes M (2013) A kinetic study of acid catalysed hydrolysis of sugar cane bagasse to levulinic acid. Chem Eng J 217:61-70. https:// doi.org/10.1016/j.cej.2012.11.094

Gouveia ER, do Nascimento RT, Souto-Maior AM, de M Rocha GJ (2009) Validação de metodologia para a caracterização química de bagaço de cana-de-açúcar. Quim Nova 32:1500-1503. 40422009000600026

Haldar D, Purkait MK (2020) Lignocellulosic conversion into value-added products: a review. Process Biochem 89:110-133. https://doi.org/10.1016/j.procbio.2019.10. 001

Islam MS, Kao N, Bhattacharya SN, Gupta R, Choi HJ (2018) Potential aspect of rice husk biomass in Australia for nanocrystalline cellulose production. Chin J Chem Eng 26:465-476. https://doi.org/10.1016/j.cjche.2017.07.004

Ji H, Dong C, Yang G, Pang Z (2019) Production of levulinic acid from lignocellulosic biomass with a recyclable aromatic acid and its kinetic study. BioResources 14:725-736. https://doi.org/10.15376/biores.14.1.725-736

Kupiainen L (2012) Dilute acid catalysed hydrolysis of cellulose-extension to formic acid. Dr. Thesis Univ. Oulu, pp 1-64

Laluce C, Roldan IU, Pecoraro E, Igbojionu LI, Ribeiro CA (2019) Effects of pretreatment applied to sugarcane bagasse on composition and morphology of cellulosic fractions. Biomass Bioenerg 126:231-238. https://doi.org/ 10.1016/j.biombioe.2019.03.002

Lappalainen K, Dong Y (2019) Simultaneous production of furfural and levulinic acid from pine sawdust via acidcatalysed mechanical depolymerization and microwave irradiation. Biomass Bioenerg 123:159-165. https://doi. org/10.1016/j.biombioe.2019.02.017

Lenihan P, Orozco A, O’Neill E, Ahmad MNM, Rooney DW, Mangwandi C, Walker GM (2011) Kinetic modelling of dilute acid hydrolysis of lignocellulosic biomass. In: Bernardes MADS (ed) Biofuel production-recent developments and prospects. IntechOpen, pp 293-308

Liu S, Wang K, Yu H, Li B, Yu S (2019) Catalytic preparation of levulinic acid from cellobiose via Brønsted-Lewis acidic ionic liquids functional catalysts. Sci Rep 9:1-9. https:// doi.org/10.1038/s41598-018-38051-y

Lopes ES, Dominices KMC, Lopes MS, Tovar LP, Filho RM (2017) A green chemical production: obtaining levulinic acid from pretreated sugarcane bagasse. Chem Eng Trans 57:145-150. https://doi.org/10.3303/CET1757025

Lopes ES, Leal Silva JF, Rivera EC, Gomes AP, Lopes MS, Maciel Filho R, Tovar LP (2020) Challenges to levulinic acid and humins valuation in the sugarcane bagasse biorefinery concept. Bioenerg Res. https://doi.org/10.1007/ s12155-020-10124-9

MAPA (2019) Ministério da Agricultura, Pecuária e Abastecimento - Projeção do Agronegócio. http://www.agricultura. gov.br/assuntos/politica-agricola/todas-publicacoes-depolitica-agricola/projecoes-do-agronegocio. Accessed 12 June 2019

Martelli-Tosi M, Assis OBG, Silva NC, Esposto BS, Martins MA, Tapia-Blácido DR (2017) Chemical treatment and characterization of soybean straw and soybean protein isolate/straw composite films. Carbohydr Polym
157:512-520. https://doi.org/10.1016/j.carbpol.2016.10. 013

Mikola M, Ahola J, Tanskanen J (2019) Production of levulinic acid from glucose in sulfolane/water mixtures. Chem Eng Res Des 148:291-297. https://doi.org/10.1016/j.cherd. 2019.06.022

Mukherjee A, Dumont MJ (2016) Levulinic acid production from starch using microwave and oil bath heating: a kinetic modeling approach. Ind Eng Chem Res 55:8941-8949. https://doi.org/10.1021/acs.iecr.6b02468

Mukherjee A, Dumont MJ, Raghavan V (2015) Review: sustainable production of hydroxymethylfurfural and levulinic acid: challenges and opportunities. Biomass Bioenerg 72:143-183. https://doi.org/10.1016/j.biombioe.2014.11. 007

Neto JM, Dos Reis GarciaD, Rueda SMG, Da Costa AC (2013) Study of kinetic parameters in a mechanistic model for enzymatic hydrolysis of sugarcane bagasse subjected to different pretreatments. Bioprocess Biosyst Eng 36:1579-1590. https://doi.org/10.1007/s00449-013-09306

NovaCana (2019) Producao de cana-de-acucar no brasil e no mundo. https://www.novacana.com/cana/producao-canade-acucar-brasil-e-mundo. Accessed 17 Oct 2019

Ozsel BK, Ozturk D, Nis B (2019) One-pot hydrothermal conversion of different residues to value-added chemicals using new acidic carbonaceous catalyst. Bioresour Technol 289:121627. https://doi.org/10.1016/j.biortech.2019. 121627

Punnathanam V, Sivadurgaprasad C, Kotecha P (2016) Multiobjective optimal integration of biorefineries using NSGAII and MOGWO. In: International conference on electrical, electronics, and optimization techniques (ICEEOT 2016). IEEE, pp 3970-3975

Qing Q, Guo Q, Wang P, Qian H, Gao X, Zhang Y (2018) Kinetics study of levulinic acid production from corncobs by tin tetrachloride as catalyst. Bioresour Technol 260:150-156. https://doi.org/10.1016/j.biortech.2018.03. 073

Rackemann DW, Doherty WO (2011) The conversion of lignocellulosics to levulinic acid. Biofuels Bioprod Biorefin 5:198-214. https://doi.org/10.1002/bbb.267

Ren H, Girisuta B, Zhou Y, Liu L (2015) Selective and recyclable depolymerization of cellulose to levulinicacid catalyzed by acidic ionic liquid. Carbohydr Polym 117:569-576. https://doi.org/10.1016/j.carbpol.2014.09. 091

Rivas S, González-Muñoz MJ, Santos V, Parajó JC (2014) Acidic processing of hemicellulosic saccharides from pine wood: product distribution and kinetic modeling. Bioresour Technol 162:192-199. https://doi.org/10.1016/j. biortech.2014.03.150

Rivas S, Vila C, Alonso JL, Santos V, Parajó JC, Leahy JJ (2019) Biorefinery processes for the valorization of Miscanthus polysaccharides: from constituent sugars to platform chemicals. Ind Crops Prod 134:309-317. https://doi. org/10.1016/j.indcrop.2019.04.005

Sangregorio A, Guigo N, van der Waal JC, Sbirrazzuoli N (2019) All 'green' composites comprising flax fibres and humins' resins. Compos Sci Technol 171:70-77. https:// doi.org/10.1016/j.compscitech.2018.12.008 
Segal L, Creely JJ, Martin AE, Conrad CM (1959) An empirical method for estimating the degree of crystallinity of native cellulose using the X-ray diffractometer. Text Res J 29:786-794. 004051755902901003

Shen J, Wyman CE (2012) Hydrochloric acid-catalyzed levulinic acid formation from cellulose: data and kinetic model to maximize yields. AIChE J 58:236-246. https://doi.org/ 10.1002/aic. 12556

Sikalo N, Hasemann O, Schulz C, Kempf A, Wlokas I (2015) A genetic algorithm-based method for the optimization of reduced kinetics mechanisms. Int $\mathrm{J}$ Chem Kinet 47:695-723. https://doi.org/10.1002/kin.20942

Sluiter A, Hames B, Ruiz R, Scarlata C, Sluiter J, Templeton D (2008a) NREL/TP-510-42623-determination of sugars, byproducts, and degradation products in liquid fraction process samples, laboratory analytical procedure (LAP). National Renewable Energy Laboratory, Golden, pp 1-11

Sluiter A, Ruiz R, Scarlata C, Sluiter J, Templeton D (2008b) NREL/TP-510-42619-determination of extractives in biomass, laboratory analytical procedure (LAP). National Renewable Energy Laboratory, Golden, pp 1-9

Sluiter A, Hames B, Ruiz R, Scarlata C, Sluiter J, Templeton D, Crocker D (2012) NREL/TP-510-42618-determination of structural carbohydrates and lignin in biomass, laboratory analytical procedure (LAP). National Renewable Energy Laboratory, Golden, pp 1-14

Tan-Soetedjo JNM, Van De Bovenkamp HH, Abdilla RM, Rasrendra CB, Van Ginkel J, Heeres HJ (2017) Experimental and kinetic modeling studies on the conversion of sucrose to levulinic acid and 5-hydroxymethylfurfural using sulfuric acid in water. Ind Eng Chem Res 56:13228-13239. https://doi.org/10.1021/acs.iecr. $7 \mathrm{~b} 01611$

Udop (2019) Moagem de cana-de-açúcar no Brasil. https:// www.udop.com.br/download/estatistica/acucar_producao/ 13fev20_moagem_cana_brasil.pdf. Accessed 24 Feb 2020

USDA (2019) Increasing Brazil imports provide relief for mercosur neighbors. https://apps.fas.usda.gov/psdonline/ circulars/grain-rice.pdf. Accessed 16 July 2019

Van de Vyver S, Thomas J, Geboers J, Keyzer S, Smet M, Dehaen W, Jacobs PA, Sels BF (2011) Catalytic production of levulinic acid from cellulose and other biomass-derived carbohydrates with sulfonated hyperbranched poly(arylene oxindole)s. Energy Environ Sci 4:3601-3610. https://doi. org/10.1039/c1ee01418h

Wang K, Ye J, Zhou M, Liu P, Liang X, Xu J, Jiang J (2017) Selective conversion of cellulose to levulinic acid and furfural in sulfolane/water solvent. Cellulose 24:1383-1394. https://doi.org/10.1007/s10570-016-11847

Wang C, Zhang Q, Chen Y, Zhang X, Xu F (2018) Highly efficient conversion of xylose residues to levulinic acid over $\mathrm{FeCl}_{3}$ catalyst in green salt solutions. ACS Sustain Chem Eng 6:3154-3161. https://doi.org/10.1021/ acssuschemeng.7b03183

Wang C, Yang G, Zhang X, Shao L, Lyu G, Mao J, Liu S, Xu F (2019) A kinetic study on the hydrolysis of corncob residues to levulinic acid in the $\mathrm{FeCl}_{3}-\mathrm{NaCl}$ system. Cellulose 26:8313-8323. https://doi.org/10.1007/s10570-01902711-7

Weingarten R, Cho J, Xing R, Conner WC, Huber GW (2012) Kinetics and reaction engineering of levulinic acid production from aqueous glucose solutions. Chemsuschem 5:1280-1290. https://doi.org/10.1002/cssc.201100717

Xiong Y, Cui X, Wang D, Wang Y, Lou Z, Shan W, Fan Y (2019) Diethanolamine functionalized rice husk for highly efficient recovery of gallium(III) from solution and a mechanism study. Mater Sci Eng C 99:1115-1122. https:// doi.org/10.1016/j.msec.2019.02.028

Zhi Z, Li N, Qiao Y, Zheng X, Wang H, Lu X (2015) Kinetic study of levulinic acid production from corn stalk at relatively high temperature using $\mathrm{FeCl}_{3}$ as catalyst: a simplified model evaluated. Ind Crops Prod 76:672-680. https:// doi.org/10.1016/j.indcrop.2015.07.058

Zhou L, Gao D, Yang J, Yang X, Su Y, Lu T (2020) Conversion of recalcitrant cellulose to alkyl levulinates and levulinic acid via oxidation pretreatment combined with alcoholysis over $\mathrm{Al}_{2}\left(\mathrm{SO}_{4}\right)_{3}$. Cellulose 27:1451-1463. https://doi.org/ 10.1007/s10570-019-02903-1

Publisher's Note Springer Nature remains neutral with regard to jurisdictional claims in published maps and institutional affiliations. 